\title{
Genetic Basis of Myocarditis: Myth or Reality?
}

\author{
Eloisa Arbustini, Nupoor Narula, Lorenzo Giuliani, \\ and Alessandro Di Toro
}

\subsection{Introduction}

\subsubsection{Definition}

The term myocarditis describes the presence of inflammatory cells in the myocardium. This descriptive diagnosis encompasses a wide spectrum of etiologically different diseases that share, as a unique criterion, the presence of myocardial inflammation [1] (Fig. 4.1). The term, however, does not specify the type of inflammation, the nature of inflammatory cells, and the cause. In clinical practice, the diagnosis of myocarditis implies that the observed phenotype is attributable to the inflammation of the myocardium or that the myocardial inflammation constitutes a "comorbidity" or "complication" of preexisting known heart disease, even of a noninflammatory nature [2].

\subsubsection{Immunocompetent Cells in Myocardial Tissue}

Unlike other organs and tissues, the myocardium does not host lymphoid tissue (e.g., BALT in lung, MALT in gastrointestinal tract) and does not possess resident

\footnotetext{
E. Arbustini $(\triangle) \cdot$ L. Giuliani · A. Di Toro

Centre for Inherited Cardiovascular Diseases - IRCCS Policlinico San Matteo, Pavia, Italy e-mail: e.arbustini@smatteo.pv.it; 1.giuliani@smatteo.pv.it; a.ditoro@smatteo.pv.it

N. Narula

Centre for Inherited Cardiovascular Diseases - IRCCS Policlinico San Matteo, Pavia, Italy

Division of Cardiology, Department of Medicine, New York Presbyterian Hospital, Weill Cornell Medicine, New York, NY, USA

e-mail: nun9005@nyp.org
} 
Fig. 4.1 The figure shows the typical features of acute lymphocytic myocarditis in an endomyocardial biopsy of a young male patient presenting with acute heart failure and elevated troponin levels

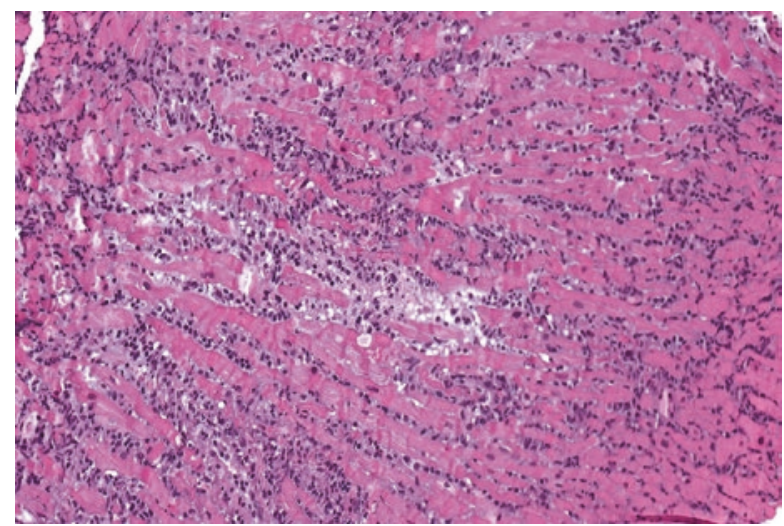

"reticulo-endothelial (RE)" cells (e.g., liver and spleen), such as alveolar macrophages in the lung, glia cells in the brain, or glomerular-mesangial cells in the kidney. However, a fair amount of steady-state, resident macrophages is present in myocardial tissue $[3,4]$. These macrophages originate from yolk sac and fetal monocytic progenitors and are either replenished by local proliferation in infancy [3] or by blood monocytes in adulthood [4]. At birth, resident macrophages express major histocompatibility complex class II (HLA II) molecules and the CX3CR1+ Fractalkine receptor and are therefore distinct from conventional $\alpha \mathrm{E}$ integrin CD103+ dendritic cells [5]. With age, the number of HLA II macrophages increases while the number of $\mathrm{CX}_{3} \mathrm{CR}_{1}+$ macrophages decreases [6]; the proliferation capacity of embryo-derived cardiac macrophages progressively declines after the perinatal period [6]. Cardiac-resident macrophages display distinct functional properties from those of monocyte-derived macrophages in cardiac tissue. Resident macrophages interweave a complex molecular dialogue with cardiac myocytes, likely mediated by cytokines; macrophages can modulate the different signals that originate from the injured cardiac tissue [7]. In cardiac inflammatory diseases, resident macrophages likely participate in attracting circulating monocytes and other inflammatory cells, depending on the local signal triggering the inflammation [8]. Therefore, the myocardial tissue is not lacking in its own immune defenses, but it does not have a structured RE system like other organs that are much more commonly the target of infections.

\subsubsection{Why Does Myocardial Tissue Trigger Inflammation?}

Myocardial tissue becomes a target of inflammation when it has to repair tissue damage (e.g., acute myocardial infarction or toxic necrosis), if the myocytes are infected by cardiotropic pathogens (infective myocarditis) or in an allogeneic condition (e.g., transplant), if other cardiac structures (valves or pericardium) become targets of inflammation due to self/pathogen mimicry mechanisms (e.g., rheumatic 
fever), or become self-reactive as in immune-mediated myocarditis, or if genetic defects induce deficiency of the immunologic system (e.g., primary immunodeficiency and auto-inflammatory diseases). The understanding of mechanisms of myocardial inflammation in infectious and non-infectious myocarditis is challenging, as it is difficult to understand whether individual constitutional gene variants can influence these mechanisms. In fact, it is noted that individuals exposed to the same pathogens may or may not develop myocarditis, even within the same environmental exposure context. This is one of the reasons why the search for predisposing genetic factors continues to attract the interest of researchers.

In this chapter, we will briefly review the main types of myocarditis and discuss individual genetic susceptibility to different types of myocarditis from both a clinical and research development perspective. Each type of myocarditis is reviewed in other chapters of this book.

\subsection{Is Myocarditis a Genetic Disease?}

Overall, myocarditis can be simply grouped by infectious, non-infectious (autoimmune, immune-mediated, or auto-inflammatory), and toxic etiologies (Table 4.1). Infectious myocarditis can be caused by DNA and RNA viruses, bacteria, fungi, protozoa, and helminths. The most common causes of infectious myocarditis in both children and adults are cardiotropic viruses [9]. Non-viral cardiotropic infections such as Trypanosoma Cruzi (Chagas disease) [10] and Borrelia burgdorferi (Lyme disease) [11] can affect immune-competent individuals in endemic areas. In immunocompromised patients, typically heart transplant recipients, the most common opportunistic infections include the human cytomegalovirus (HCMV) and Toxoplasma gondii. The state of knowledge on the etiology, diagnosis, management, and therapy of myocarditis and that on the diagnosis and management of myocardial involvement in systemic immune-mediated diseases are reported in two position statements of the European Society of cardiology [12, 13].

Precise rules define the criteria for the diagnosis of systemic and organ involvement [14], including the heart. Myocardial involvement is diagnosed when the infectious agent is detected in myocardial tissue by pathologic and pathogen-related genomic studies $[12,13]$. Often, in clinical practice, the diagnosis of myocarditis is suspected, based more on clinical, biochemical, and imaging criteria than on the demonstration of myocardial tissue inflammation. Failure to precisely diagnose the cause can lead to overlooking a potentially toxic origin (e.g., pheochromocytoma) [15] and genetic familial diseases with similar clinical expression. Resuscitated cardiac arrest is one of the examples in which imaging-detected interstitial edema [15] can lead to incorrect diagnostic hypotheses. As expected, infectious myocarditis is not a genetic disease; in the absence of the pathogen, there is no myocarditis. However, the role of genetic susceptibility has been repeatedly raised in clinical and experimental studies in an attempt to understand why some individuals develop myocarditis, while others, perhaps exposed to the same risk, do not. 


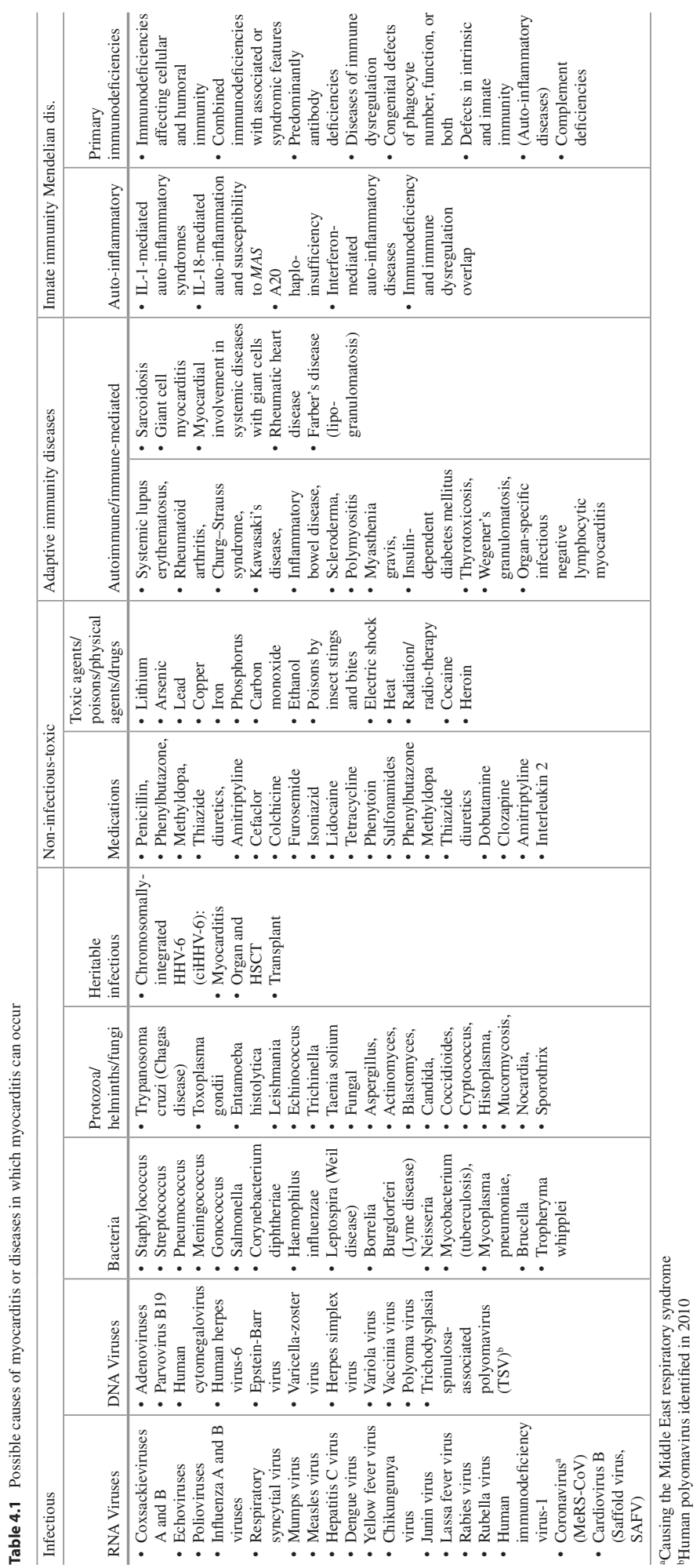




\subsection{Infectious Myocarditis and Genetics}

Reasons to suspect a genetic susceptibility in infectious myocarditis may derive from twin studies (usually newborn or children) [16-18], familial clustering suggesting genetic determinants or predisposing genetic factors [19-21], and rare Mendelian diseases $[22,23]$ as well as endemic infections linked to both pathogen and population genetic make-up [24]. The topic must be discussed with caution so as not to transform infectious diseases into genetic ones, especially as the distinction between genetic susceptibility from exclusive environmental factors that might aggregate within families can be difficult.

\subsubsection{Single Gene Defects and Myocarditis}

"Mendelian" myocarditis is rare, and the available information is based on single case reports and small clinical series. Disease genes are either immunity genes or non-immunity genes whose defects cause heritable cardiomyopathies [2] and may eventually predispose to myocarditis.

\subsubsection{Immunity Genes}

These are cases of apparently sporadic myocarditis in patients with "primary immunodeficiency diseases" (PID), mainly autosomal recessive, which predispose to infections including those that cause myocarditis [25]. PID phenotypes are heterogeneous overall [26-28], and the genetic cause is not the infection itself, but the condition of immunodeficiency that underlies the predisposition and the occurrence of myocarditis. PIDs are predominantly observed in the pediatric age as the case of a child with disseminated Mycobacterium avium infection carrier of IL-12R $\beta 1$ deficiency due to compound heterozygosity and who ultimately died of acute heart failure due to a Coxsackie myocarditis and a poor nutritional status [29]. In the adult it is rarer but possible. A toll-like receptor 3 mutation has been identified in an adult patient diagnosed with enteroviral (EV) myocarditis [30].

\subsubsection{Non-immunity Genes: Do Genetic Cardiomyopathies Display Susceptibility to Myocarditis?}

The possibility of deep molecular and genetic exploration of heart diseases may contribute to unravel the molecular pathogenetic mechanisms of heart diseases, either predisposition of genetic cardiomyopathies to infections which may trigger the first manifestation of the disease or simply infectious complications in patients with an established diagnosis of genetic cardiomyopathy. The question is whether genetically affected hearts are more vulnerable to inflammatory triggers than nonaffected hearts $[2,31]$. A recent in vitro and clinical study explored the hypothesis that human genetic factors might underlie acute viral myocarditis in previously healthy children. Authors tested the role of TLR3-interferon (IFN) immunity using human-induced pluripotent stem cell-derived cardiomyocytes (iPSC-CM) and performed whole-exome sequencing in 42 unrelated children with acute myocarditis, 
some with proven viral etiologies. TLR3- and STAT1-deficient iPSC-CM did not show more susceptibility to coxsackievirus B3 (CVB3) infection than control cells. CVB3 did not induce IFN- $\alpha / \beta$ and IFN- $\alpha / \beta$-stimulated genes in control cardiomyocytes and exogenous IFN- $\alpha$ did not substantially protect cardiomyocytes against CVB3. Exome sequencing did not show mutations in TLR3- or IFN- $\alpha / \beta$-related genes. Unexpectedly, seven of 42 patients (16.7\%) were carriers of rare bi-allelic, nonsynonymous, or splice-site variations in six cardiomyopathy-associated genes (BAG3, DSP , PKP2, RYR2, SCN5A, or TNNI3). The authors concluded that "previously silent recessive defects of the myocardium may predispose to acute heart failure presenting as acute myocarditis, notably after common viral infections" [32]. The hypothesis that acute myocarditis reflects an active phase of ARVD that leads to changes in phenotype and abrupt progression of the disease has been investigated by Lopez-Ayala and colleagues [33]. They suggest that an active phase should be suspected in a patient with myocarditis associated with a family history of ARVD and that certain mutations may increase the susceptibility to superimposed myocarditis in ARVD [33]. Patients with dilated cardiomyopathy caused by defects of $d y s-$ trophin and dysferlin demonstrate increased susceptibility to myocardial CVB3 infection by enhancing viral propagation to adjacent cardiomyocytes and disrupting the function that repairs the myocyte membrane [34-36]. The history of a recent flu episode in patients with XL-DCM caused by defects of dystrophin may confound the true clinical diagnosis, but the possibility that a viral flu triggers or unmasks the manifestation of preexisting asymptomatic disease cannot be excluded. Although myocarditis and the viral genome may not be found in the EMB from patients with XL-DCM [37], the myocardium with dystrophin defects could sustain greater damage from coxsackievirus proteases that are known to affect host cell proteins such as dystrophin [34-37]. As confirmation of the role or effect of myocarditis on the expression of dystrophin, there is evidence of focal disruption of the dystrophinglycoprotein complex (DGC) in human coxsackievirus B myocarditis. DGC disruption can contribute to the pathogenesis of human enterovirus (EV)-induced dilated cardiomyopathy [38], and the disintegration of the sarcoglycan complex may, in addition to dystrophin cleavage, play an important role in the pathogenesis of enterovirus-induced cardiomyopathy [39].

\subsubsection{Genetic Susceptibility and Enteroviral Myocarditis}

The clinical presentation of EV infection may be relatively mild (fever, herpangina, conjunctivitis, hand-foot-mouth disease, tonsillitis, pharyngitis, lower respiratory tract infection, acute gastroenteritis) or, less commonly, very severe (pneumonia, meningitis, encephalitis, myocarditis, pericarditis, hepatic necrosis, and coagulopathy) [40]. EV myocarditis is often described in outbreaks of EV infections [41-46] (Table 4.2). The cardiotropic coxsackievirus B3 (CV-B3) is one of the most common causes of myocarditis [40]. The myocardial infection is initiated by the transmembrane coxsackievirus-adenovirus receptor (CAR) encoded by the CXADR gene $(\mathrm{MIM} * 602621)$; in experimental models, the ablation of CAR blocks viral infection of myocardial cells as well as inflammation in the myocardium [47]. Similarly, 
Table 4.2 Enterovirus, outbreaks, and reports of EV myocarditis

\begin{tabular}{|c|c|c|c|}
\hline Species & Types & $\begin{array}{l}\text { Outbreaks with reports of } \\
\text { myocarditis }\end{array}$ & Ref \\
\hline A & $\begin{array}{l}\text { - Coxsackievirus 1-8, 10, 12, 14, 16; } \\
\text { - Enterovirus A71, A76, A89, A90, } \\
\text { A114, A119, A120, A121 }\end{array}$ & $\begin{array}{l}\text { Severe hand-foot and mouth } \\
\text { disease due to CVA6, } \\
\text { CVA16, and A71 }\end{array}$ & {$[41,42]$} \\
\hline B & $\begin{array}{l}\text { - Coxsackie B 1-6, A9, } \\
\text { - Echovirus 1-7, 9,11-21, 24-27, 29-33 } \\
\text { - Enterovirus B 69, 73-75, 77-88, 93, } \\
\text { 97, 98, 100, 101, } 106 \text { and } 107\end{array}$ & Neonatal sepsis due to CVB1 & {$[43,44]$} \\
\hline $\mathrm{C}$ & $\begin{array}{l}\text { - Coxsackie virus A1, 11, 13, 17, 19, } \\
\text { 20, 21, 22, 24; } \\
\text { - Enterovirus C 95, 96, 99, 102, 104, } \\
\text { 105, 109, 113, 116-118; } \\
\text { - Poliovirus } 1-3\end{array}$ & $\begin{array}{l}\text { Small outbreaks of cVDPV } \\
\text { and paralytic disease due to } \\
\text { newer EV-C viruses }\end{array}$ & {$[45]$} \\
\hline D & - EV D68 D70, D94, D111 & $\begin{array}{l}\text { Reports of EVD68 respiratory } \\
\text { diseases, including } \\
\text { myocarditis. Association with } \\
\text { acute flaccid myelitis }\end{array}$ & [46] \\
\hline
\end{tabular}

increased cardiac expression of CAR may partially explain increased susceptibility to myocarditis [48]. However, to date, mutations in the CXADR gene have not been reported/identified. In CVB3-infected myocytes, the cell damage is induced by direct cytotoxicity and mediated by viral proteinases [49]. CVB3 replicates on the surface of autophagosomes $[50,51]$ and enhances replication by employing miRNA $[52,53]$. CVB3-induced differential expression of miRNA modulates the expression of both host and viral genes.

Individual genetic make-up may favor EV infection. A recent investigation focuses on PI4KB/ACBD3 (phosphatidylinositol kinase 4, type 3 beta/acyl-CoAbinding domain-containing protein 3) interaction as facilitating mechanisms for efficient viral replication. Enteroviruses, as well as other positive-strand RNA viruses, reorganize host cellular membranes through recruiting phosphatidylinositol (PI) 4-kinase $(P I 4 K B)$, whose defects cause the monogenic autosomal recessive perisylvian polymicrogyria, with cerebellar hypoplasia and arthrogryposis [54]. Acute inhibition of the enzyme PI4KA by kinase inhibitors causes sudden death [55]. The Golgi-residing protein, ACBD3 (Golgi phosphoprotein 1; GOLPH1), which is involved in the maintenance of Golgi structure and function, is responsible for proper localization of enteroviral 3A proteins in host cells. Mutants abrogating the ACBD3-PI4KB interaction showed that this interaction is crucial for enterovirus replication and allowed the identification of the minimal ACBD3 domains that are essential for enterovirus replication. Therefore, acyl-coenzyme A binding (ACB) and charged-amino-acid region (CAR) domains are dispensable for 3A-mediated PI4KB recruitment and efficient enterovirus replication [56]. The myocardial expression of NOD2 (nucleotide-binding oligomerization domain protein 2) gene has also been found to be higher in CVB3-positive patients compared with patients with myocarditis but without evidence of persistent CVB3 infection; no genetic variants in the gene have been reported to date [57]. 


\subsubsection{Parvovirus B19 and Myocarditis: Genetic Studies Unravel Molecular Mechanisms But Do Not Demonstrate Heritable Predisposition}

Human parvovirus B19 (B19V) belongs to genus Erythroparvovirus of the Parvoviridae family, which is composed of a group of DNA viruses with a linear single-stranded DNA genome [58]. B19V infects human erythroid progenitor cells (EPCs) and causes mild to severe hematological disorders [59]. It may also infect non-erythroid lineage cells such as myocardial endothelial cells [60]. The tropism of B19V for EPCs depends on the expression of viral receptors and coreceptors on the cell surface and by the viral use of host factors such as RNA binding motif protein 38 (RBM38) for the processing of its pre-mRNA during viral replication [61]. Variants in $R B M 38$ gene have not been reported so far. The RBM38 protein (coded by the RBM38 gene, 20q13.31, MIM*612428) interacts with the intronic splicing enhancer 2 (ISE2) element of B19V premRNA and promotes $11-\mathrm{kDa}$ protein expression that regulates the 11-kDa protein-mediated augmentation of B19V replication [62]. The B19V-antibody complex enters the cells through an endocytosis process mediated by the direct interaction of antibody-bound complement factor $\mathrm{C} 1 \mathrm{q}$ with its receptor CD93 on the cell surface [63].

Infection by PVB19 causes fifth disease, arthropathy, anemia in immunocompromised patients and sickle cell disease patients, myocarditis, and hydrops fetalis in pregnant women [64-66]. The cardiac manifestations vary, from mild and nonspecific symptoms (e.g., fatigue, arrhythmias) to severe, including cardiogenic shock requiring mechanical support. PCR-based studies have reported B19V genome in myocardial tissue of patients with myocarditis and dilated cardiomyopathy, however also in control cases, disproving the hypothesis that persistent myocardial viral infection might be a frequent cause of DCM or myocarditis [6769]. Similar findings have been reported in skin samples from patients with dermatological diseases in which the role of viral infection is debated [70]. It should be considered that no biopsy tissue sample is blood-free. In addition, remnant B19V DNA strands can be released from tissues without active viral replication; therefore, the PCR-based detection of B19V DNA in blood does not prove the presence of infectious virions and viral replication [71]. This finding suggests caution in the interpretation of the role of B19V infection when based on B19V DNA detection in blood, not only in myocarditis but also in other diseases that have been hypothesized to be causally linked with B19V. Finally, the viral load of PVB19 genomes in the myocardium is not related to the long-term outcome [72]. A possible hypothesis that could explain the role of B19V in myocarditis and cardiomyopathy is the potential trigger effect of the viral genome for innate immunity, inducing pro-inflammatory cytokine secretion [72] and myocardial inflammation. Although the hypothesis that individual susceptibility and modifier genes may influence the predisposition to myocarditis, there is no current proven evidence of gene variants potentially exerting this role. 


\subsubsection{Herpes Virus Infections: Heritability of Chromosomally Integrated HHV-6 (ciHHV-6)}

A recently described case of myocarditis in a patient with chromosomally integrated HHV-6 (ciHHV-6) [73] links the herpes virus infection with an inherited risk of myocarditis. ciHHV-6 is a rare heritable condition in which the complete genome of the virus is integrated into the host germline genome (OMIM 604474) [74]. ciHHV-6 is characterized by high viral copy numbers in blood or sera ( $>6 \log (10)$ copies $/ \mathrm{mL}$ ) with a prevalence of $0.8 \%$ of UK blood donors. Therefore, the finding of high HHV-6 viral loads in healthy normal individuals highlights the need to correctly interpret ciHHV-6, with its possible confounding effect in laboratory diagnosis of HHV-6 infection [75, 76] or its role in patients with DCM/heart failure [77]. The integrated viral genome eventually secreting viral chemokines can confer human genes with links to inflammatory pathology and supports ciHHV-6A reactivation as a source for emergent infection $[77,78]$.

\subsubsection{Chagas Disease and Genetic Predisposition}

Chagas disease (CD) is caused by the protozoan parasite Trypanosoma cruzi [79] through direct oral contact, contaminated blood transfusion, or bone marrow transplantation. There may also be vertical transmission from the mother to infant. CD is endemic in the southern USA, Mexico, Central America, and South America [10, 79, 80]. Contamination of food and drink has been reported in northern South America, where transmission cycles may involve wild vector populations and mammalian reservoir hosts $[10,79-82]$. In the acute phase, the disease can manifest with myocarditis, conduction system abnormalities, and pericarditis. In untreated patients, the disease progresses to the chronic phase with development of chronic Chagas cardiomyopathy (CCC) [79]. Genetic susceptibility to the development of CCC is a matter of ongoing investigation of immunity genes to identify possible individual and population-based predisposition. Table 4.3 [83-91] lists the genes and related variants investigated to date in $\mathrm{CD}$. Although some association studies tested positive, no genetic test is currently performed in the diagnostic work-up of CD.

\subsubsection{Rheumatic Fever, Carditis, and Genetics}

Rheumatic fever (RF) is an immune-mediated disease that affects predominantly children and adolescents in low-income and developing countries, in which the disease burden is still relevant $[92,93]$. RF occurs in "genetically susceptible individuals", as sequelae of Group A Streptococcus (GAS) pyogenes infection. The clinical manifestations depend upon the tissues involved, including synovium (arthritis), heart valves (endocarditis), myocardium (pancarditis), brain 
Table 4.3 Genetic association studies for susceptibility to Chagas Disease (CD) and pathophysiology of Chronic Chagas Cardiomyopathy (CCC)

\begin{tabular}{|c|c|c|c|c|c|}
\hline \multirow[b]{2}{*}{ Gene } & \multirow[b]{2}{*}{ Peptide } & \multicolumn{2}{|c|}{$\begin{array}{l}\text { Monogenic disease and } \\
\text { susceptibility in OMIM }\end{array}$} & \multicolumn{2}{|c|}{$\begin{array}{l}\text { Genetic variants variably } \\
\text { associated with Chagas } \\
\text { Disease }\end{array}$} \\
\hline & & MIM Phenotype & Inheritance & & Ref \\
\hline COLEC11 & Collectin 11 & $3 \mathrm{MC}$ syndrome 2 & AR & \multirow{2}{*}{$\begin{array}{l}\text { Association with } \\
\text { the } \\
\text { pathophysiology of } \\
\text { Chagas disease }\end{array}$} & \multirow[t]{2}{*}{ [83] } \\
\hline MASP2 & $\begin{array}{l}\text { Lectin } \\
\text { complement } \\
\text { activation } \\
\text { pathway, defect, } 2\end{array}$ & MASP2 deficiency & AR & & \\
\hline $\begin{array}{l}\text { Promoter region, } \\
\text { IL18 }\end{array}$ & Interleukin 18 & - & - & $\begin{array}{l}\text { Susceptibility to } \\
\text { CD }\end{array}$ & [84] \\
\hline $\begin{array}{l}\text { VDR gene } \\
\text { (rs731236, } \\
\text { rs7975232, } \\
\text { rs1544410 and } \\
\text { rs2228570) }\end{array}$ & $\begin{array}{l}\text { Vitamin D } \\
\text { receptor }\end{array}$ & $\begin{array}{l}\text { Rickets, vitamin } \\
\text { D-resistant, type IIA }\end{array}$ & $\mathrm{AR}$ & $\begin{array}{l}\text { rs } 2228570 * \mathrm{~A} \\
\text { allele: Association } \\
\text { with CD }\end{array}$ & [85] \\
\hline $\begin{array}{l}\text { IL17A G197A } \\
\text { (rs2275913) }\end{array}$ & Interleukin 17A & - & - & \multirow[t]{2}{*}{$\begin{array}{l}\text { Association with } \\
\text { Chagas disease }\end{array}$} & \multirow[t]{2}{*}{ [86] } \\
\hline $\begin{array}{l}\text { IL17F T7488C } \\
\text { (rs763780) }\end{array}$ & Interleukin 17F & $\begin{array}{l}\text { Familial candidiasis, } \\
6\end{array}$ & $\mathrm{AD}$ & & \\
\hline $\begin{array}{l}\text { CCR5 } \rightarrow \Delta 32 \\
(\mathrm{rs} 333) 59029 \\
\mathrm{~A} / \mathrm{G} \\
(\mathrm{pm} \text { rs1799987) }\end{array}$ & $\begin{array}{l}\text { Chemochine, } \\
\text { CR motif, } 5\end{array}$ & \multirow[t]{2}{*}{$\begin{array}{l}\text { - Susceptibility/ } \\
\text { resistance to HIV } \\
\text { infection } \\
\text { - West Nile virus, } \\
\text { susceptibility to }\end{array}$} & - & $\begin{array}{l}\text { CCR5 } \Delta 32 \text { no } \\
\text { CCR5 59,029 A/G } \\
\text { yes } \\
\text { Association with } \\
\text { CCC }\end{array}$ & [87] \\
\hline $\begin{array}{l}\text { CCR2-CCR5 } \\
\text { genes and their } \\
\text { haplotypes }\end{array}$ & $\begin{array}{l}\text { Chemochine, } \\
\text { CR motif, } 2 \\
\text { Chemochine, } \\
\text { CR motif, } 5\end{array}$ & & - & $\begin{array}{l}\text { Association with } \\
\text { CCC }\end{array}$ & [88] \\
\hline $\begin{array}{l}\text { - TGFB1: } \\
\text { rs8179181, } \\
\text { rs8105161, } \\
\text { rs1800469; }\end{array}$ & $\begin{array}{l}\text { - Transforming } \\
\text { growth factor B } 1\end{array}$ & $\begin{array}{l}\text { - Camurati- } \\
\text { Engelmann disease }\end{array}$ & - $\mathrm{AD}$ & \multirow[t]{8}{*}{$\begin{array}{l}\text { No association with } \\
\text { clinical outcome in } \\
\text { CCC }\end{array}$} & \multirow[t]{8}{*}{ [89] } \\
\hline $\begin{array}{l}\text { - IL10: } \\
\text { rs1800890, } \\
\text { rs1800871, } \\
\text { rs1800896; }\end{array}$ & - Interleukin 10 & $\begin{array}{l}\text { - HIV susceptibility; } \\
\text { RA progression }\end{array}$ & $\cdot-$ & & \\
\hline $\begin{array}{l}\text { - IFNG: } \\
\text { rs2430561; }\end{array}$ & $\begin{array}{l}\text { - Interferon } \\
\text { gamma }\end{array}$ & $\begin{array}{l}\text { TSC2 } \\
\text { angiomyolipomas, } \\
\text { renal, Mod. }\end{array}$ & - $\mathrm{AD}$ & & \\
\hline $\begin{array}{l}\text { - TNF: } \\
\text { rs1800629; }\end{array}$ & $\begin{array}{l}\text { - Tumor necrosis } \\
\text { factor }\end{array}$ & $\begin{array}{l}\text { - Asthma and Sepsis } \\
\text { susceptibility }\end{array}$ & $\cdot-$ & & \\
\hline $\begin{array}{l}\cdot \text { BAT1 } \\
\text { (DDX39B): } \\
\text { rs3853601; }\end{array}$ & $\begin{array}{l}\text { HLA-B- } \\
\text { associated } \\
\text { transcript } 1\end{array}$ & $\cdot-$ & $\cdot-$ & & \\
\hline $\begin{array}{l}\text { LTA: } \\
\text { rs909253, } \\
\text { rs2239704; }\end{array}$ & $\begin{array}{l}\text { - Lymphotoxin } \\
\text { alpha }\end{array}$ & $\begin{array}{l}\text { - Leprosy and } \\
\text { Psoriatic ar. } \\
\text { susceptibility }\end{array}$ & $\cdot-$ & & \\
\hline $\begin{array}{l}\text { - TNFR1 } \\
\text { (TNFRSF1A): } \\
\text { rs767455; }\end{array}$ & $\begin{array}{l}\text { - Tumor necrosis } \\
\text { factor receptor } 1\end{array}$ & $\begin{array}{l}\text { - Periodic familial } \\
\text { fever }\end{array}$ & - AR & & \\
\hline $\begin{array}{l}\text { - TNFR2 } \\
\text { (TNFRSF1B): } \\
\text { rs1061624. }\end{array}$ & $\begin{array}{l}\text { - Tumor necrosis } \\
\text { factor receptor } 2\end{array}$ & $\cdot-$ & $\cdot-$ & & \\
\hline
\end{tabular}


Table 4.3 (continued)

\begin{tabular}{|c|c|c|c|c|c|}
\hline \multirow[b]{2}{*}{ Gene } & \multirow[b]{2}{*}{ Peptide } & \multicolumn{2}{|c|}{$\begin{array}{l}\text { Monogenic disease and } \\
\text { susceptibility in OMIM }\end{array}$} & \multicolumn{2}{|c|}{$\begin{array}{l}\text { Genetic variants variably } \\
\text { associated with Chagas } \\
\text { Disease }\end{array}$} \\
\hline & & MIM Phenotype & Inheritance & & Ref \\
\hline $\begin{array}{l}\text { NLRP1 } \\
\text { rs11651270, }\end{array}$ & $\begin{array}{l}\text { NLR family, pyrin } \\
\text { domain containing } \\
1\end{array}$ & $\begin{array}{l}\text { Auto-inflammation } \\
\text { with arthritis and } \\
\text { dyskeratosis }\end{array}$ & $\mathrm{AD}, \mathrm{AR}$ & \multirow{3}{*}{$\begin{array}{l}\text { NLRP1 rs11651270 } \\
\text { \& CARD } \\
\text { rs6953573: } \\
\text { Association with } \\
\text { CCC }\end{array}$} & \multirow[t]{3}{*}{ [90] } \\
\hline $\begin{array}{l}\text { CARD (NOD2) } \\
\text { rs6953573 }\end{array}$ & $\begin{array}{l}\text { Caspase } \\
\text { recruitment } \\
\text { domain containing } \\
\text { protein } 15\end{array}$ & Blau syndrome & $\mathrm{AD}$ & & \\
\hline CASP1P2 & $\begin{array}{l}\text { Caspase } 1 \\
\text { apoptosis-related } \\
\text { cysteine protease }\end{array}$ & - & - & & \\
\hline $\begin{array}{l}\text { TYK2 gene } \\
\text { variants }\end{array}$ & Tyrosine kinase & Immunodeficiency 35 & AR & $\begin{array}{l}\text { Negative } \\
\text { susceptibility study }\end{array}$ & [91] \\
\hline
\end{tabular}

anflammatory bowel disease, immunodeficiency, and encephalopathy

(Sydenham's chorea), kidney (glomerulonephritis), skin (erythema marginatum), and subcutaneous tissue (rheumatic nodules). Rheumatic heart disease (RHD) is the most common acquired cardiovascular disease in youths [2] and is associated with high morbidity and mortality [94].

\subsubsection{Familial Susceptibility}

Genetic susceptibility has repeatedly been claimed as a contributor to the pathogenesis of RHD, but, to date, no significant result has been identified or reproduced with GWAS study [95]. Rheumatic fever is an example of familial "non-genetic aggregation" and of difficulties in distinguishing familial genetic susceptibility from transient or persistent environmental factors to which members of the same families may be exposed. Historical research focused attention on family aggregation [96], exploring the field of immunogenetics. An early study published in Nature in 1979 [97] identified the B-cell alloantigen marker, 883, in patients previously diagnosed with RF with or without subsequent RHD. The 883 antigen on B cells was found in $71 \%$ of patients typed in New York and $74 \%$ of patients typed in Bogota as compared with $17 \%$ in the two disease-free control groups. The marker was not associated with any of the known major histocompatibility complex (MHC) antigens. A later study showed that two antibodies produced against this antigen were present in $92 \%$ of patients as compared with $21 \%$ of disease-free controls [98]. Another monoclonal antibody, labeled D8/17, which identified a B-cell antigen present in $100 \%$ of RF patients, was found in 14.6 and $13 \%$ of unaffected sibs and parents, respectively. The segregation of phenotypes (percentage D8/17-positive cells within HLA-typed rheumatic fever families) was consistent with autosomal recessive inheritance, which was not associated with the MHC gene system [99]. The D8/17 antibody was later considered a disease-specific marker with worldwide distribution: it may serve as a diagnostic tool in patients with suspected rheumatic fever [100]. Therefore, the hypothesis of an autosomal familial recessive 
predisposition/susceptibility that was not related to HLA genes remains doubtful. Nonetheless, more recent twin pairs' studies demonstrated a concordant risk for acute rheumatic fever of $44 \%$ in monozygotic twins and $12 \%$ in dizygotic twins. The estimated heritability across six meta-analyzed studies was 60\% [101].

Genetic variants associated with increased risk of RHD have been investigated on the basis of the hypothesis that cytokine gene polymorphisms could play a role in the susceptibility of RHD in patients: TNF- $\alpha(-308 \mathrm{G}>\mathrm{A})$ and IL- $1 \beta(-511 \mathrm{C}>\mathrm{T})$ were significantly associated with increased risk of RHD, while IL-10 (-1082G>A) and IL-6 $(-174 \mathrm{G}>\mathrm{C})$ were not associated with modified RHD risk [102]. Thereafter, research focused on the role of functional variants in genes encoding molecules of the complement activation pathways. The rationale is that tissue damage in RHD is mediated by autoantibodies resulting from molecular mimicry between GAS and cardiac tissue proteins. The GAS molecule N-acetyl- $\beta$-D-glucosamine (GlcNAc) and the $\mathrm{M}$ protein cross-react with valve and myocyte proteins of the host [103]. GlcNAc is the immunodominant cell wall antigenic epitope of GAS and is recognized by ficolins [104] that comprise pattern-recognition receptors (PRRs) of the complement [103, 105]. Of the three human ficolins [ficolin-1 (M-ficolin), ficolin-2 (L-ficolin), and ficolin-3 (H-ficolin also known as Hakata antigen)] [106], ficolin-1 is found both in soluble form and on the cell membrane [107-109] and binds sialic acid to capsular polysaccharides of pathogens including Streptococcus agalactiae $[110,111]$. The levels of expression of ficolin- 1 are influenced by promoter gene variants, all associated with increased FCN1 gene expression in whole blood or adipose subcutaneous tissue, but are also associated with increased protection against the disease $[112,113]$. FCN1 polymorphisms may play a dual role in the physiopathology of RF. On the one hand, they increase the GAS infection and predispose the patient to RHD symptoms, once the infection is established [113]. Polymorphisms associated with low levels of L-ficolin level may predispose carriers to recurrent and/or more severe streptococcal infection [112]. The low levels of ficolin-1 levels reported in RHD have been interpreted as an effect of the considerable ficolin-1 consumption in RF (Table 4.4). In any case, ficolin-1 is a promising therapeutic target for autoimmune diseases [114].

FLC3 gene defects are associated with immunodeficiency due to ficolin-3 deficiency (MIM \# 613860), an autosomal recessive disease characterized by increased susceptibility to infections and autoimmune diseases, and by defect in the lectin

Table 4.4 Ficolin levels in autoimmune diseases [115]

\begin{tabular}{l|l|l|l|l|l}
\hline \multirow{2}{*}{ Disease } & \multicolumn{3}{|l|}{ Ficolin-1 levels } & CRP correlations & \multirow{2}{*}{ REF } \\
\cline { 2 - 6 } & High & Low & Unmodified & $\left(\mathrm{mg} \mathrm{dL}^{-1}\right)$ & RE \\
\hline Rheumatic fever & & + & & - & {$[112]$} \\
\hline Vasculitis & + & & & $0.98[0.19,6.71]$ & {$[113]$} \\
\hline Rheumatoid arthritis & + & & & $0.81[0.06,2.52]$ & \\
\hline Myositis & & & + & $0.20[0.04,0.63]$ & \\
\hline Systemic lupus erythematosus & & & + & $0.15[0.10,0.48]$ & \\
\hline Behcet's disease & & & + & $0.05[0.04,0.80]$ & \\
\hline
\end{tabular}



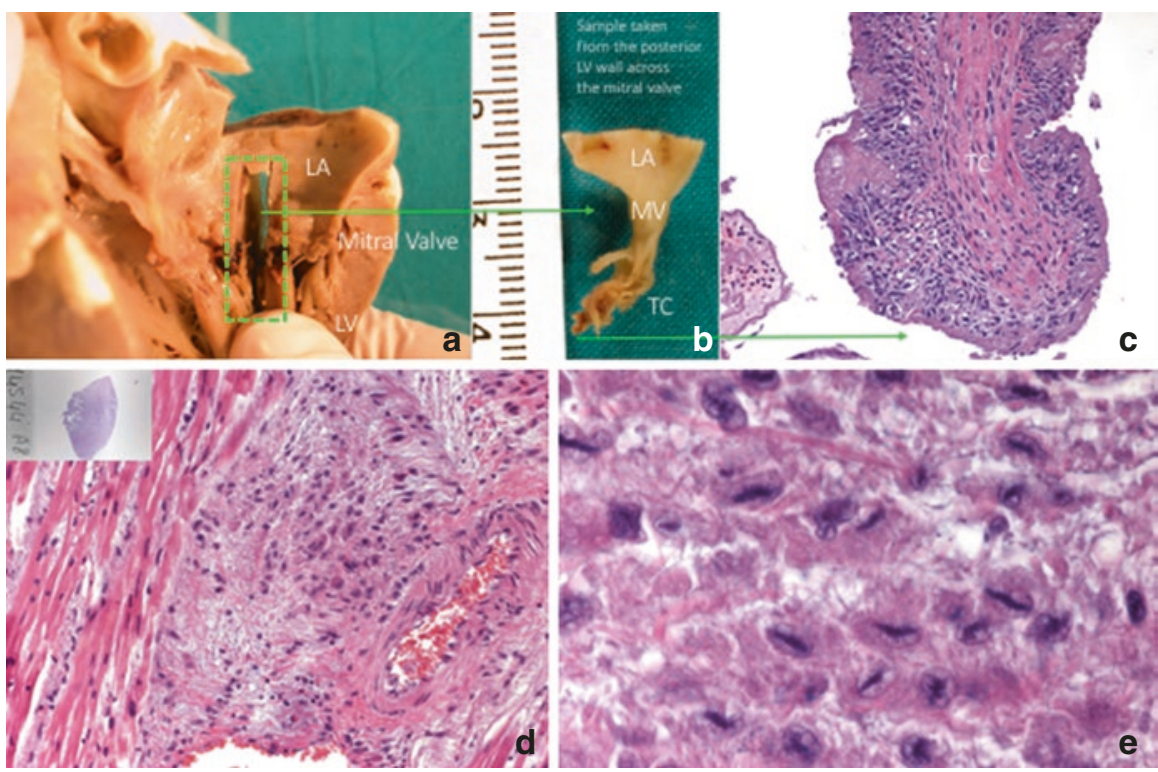

Fig. 4.2 Fatal rheumatic pancarditis with mitral chordal rupture in a boy with autosomal dominant osteogenesis imperfecta. The figure shows (a) the macroscopic view of the posterior atrioventricular wall. The sample in the (b) corresponds to the squared area in panel (a) and the histological panel (c) shows a ruptured chorda surrounded by inflammatory cells. The myocardial wall was extensively involved (d, e) and demonstrated the typical Anitschkow cells

activation pathway of the complement system. The specific biomarker is the decreased serum levels of ficolin-3. FLC3 deficiency is a rare disease of major scientific and clinical interest because heterozygous carriers have $50 \%$ reduction in circulating ficolin-3 levels. To date, only one case of cardiac disease has been described in an 11-month-old male infant who was operated on to repair a congenital heart defect [115]. Finally, the possibility exists that patients with genetic disease are more susceptible to RF [116]. This is a new area of clinical observation that also deserves attention due to the increasing number of genetic diseases that can now be correctly diagnosed [2]. As an example, the figure shows the case of a fatal rheumatic pancarditis in a boy with osteogenesis imperfecta (Fig. 4.2).

\subsection{Non-Infectious Myocarditis}

\subsubsection{Sarcoidosis}

Sarcoidosis is a chronic multisystem inflammatory disease of unknown etiology whose pathologic hallmark includes non-caseating, epithelioid granulomas primarily in the lungs and lung-draining lymph nodes [117, 118]. Sarcoidosis is considered a T-cell driven inflammatory disease in which mononuclear phagocytes 
(macrophages, monocytes, and dendritic cells) initiate and maintain T-cell activation and release cytokines that contribute to granuloma formation and maintenance $[118,119]$. The data on incidence range from $3-4$ to $35-80$ per 100,000 , reflecting ethnicity, geographic distribution, and gender. The prevalence is 10-40/100,000 persons in the USA and Europe, higher in the Scandinavian population, and lower in those of Turkish descent; in addition, the ratio of prevalence between African Americans and Caucasians is 10-17 to 1. Young women (20-40 years) are preferentially affected [119-121]. Cardiac involvement is influenced by ethnicity, approaching up to $58 \%$, and constitutes the cause of death in up to $85 \%$ of Japanese patients $[120,122]$. The disease typically occurs in the adult age; in children with suspected sarcoidosis, the autosomal dominant Blau syndrome has to be considered [123, 124]. This early aggressive form is associated with heterozygous mutations in CARD15 gene (NOD1) (MIM*605956) that cause constitutive NF-kappa-B activation [125].

The clinical manifestations of sarcoidosis are heterogeneous due to the involvement of many organs/organ systems and consist of polyarthritis, iridocyclitis, skin rash, and arteritis, in addition to potential heart, kidney, and nervous system involvement $[117,118,124]$. The heart is affected in $2-7 \%$ of patients diagnosed with systemic sarcoidosis $[117,122]$ (Fig. 4.3). Cardiac involvement is clinically manifest in about $5 \%$ of patients with sarcoidosis (sarcoid granulomas can be clinically silent), while it is asymptomatic in about $25 \%$ of cases, as confirmed by pathology, i.e., autopsy studies $[126,127]$, and imaging series, either CMR or fluorodeoxyglucose positron emission tomography (PET) [128, 129]. Simultaneous PET/MR increases the diagnostic accuracy and offers complementary information on disease pathophysiology $[129,130]$. Therefore, given that sarcoid granulomas can be clinically silent, the real proportion of cardiac sarcoidosis is likely higher than clinically apparent.

Sarcoidosis can manifest acutely (Löfgren's syndrome) or with gradual onset (non-Löfgren's syndrome). The acute Löfgren's syndrome is characterized by hilar lymphadenopathy, erythema nodosum, and fever [131]; it mainly affects women and is common in Scandinavian, Irish, African, and Puerto Rican populations. The prognosis is good, with $>90 \%$ of patients experiencing disease resolution within 2 years. On the other hand, resolution is difficult when lupus pernio, cardiac, or neurologic involvement is present.

\subsubsection{Familial Monogenic Sarcoidosis: The BLAU Syndrome and Early-Onset Sarcoidosis (EOS)}

Blau syndrome is an early-onset, chronic, granulomatous auto-inflammatory disease that is inherited by an autosomal dominant pattern [124]. The original clinical manifestations were described as a triad constituted by granulomatous dermatitis, arthritis, and uveitis [124]. Additional manifestations include erythema nodosum, fever, sialadenitis, lymphadenopathy, leukocytoclastic vasculitis, transient neuropathies, granulomatous glomerular and interstitial nephritis, interstitial lung disease, arterial hypertension, pulmonary hypertension, pericarditis, pulmonary embolism, hepatic granulomas, splenic involvement, and chronic renal failure [132-138]. Cardiac involvement is rare [136-140]. The pathologic hallmark is the 
Fig. 4.3 End-stage fibrotic phase of adult-onset sarcoidosis. The patient underwent heart transplantation because of the extensive, multifocal scarring (a); residual giant cells are visible, with asteroid bodies, both $\mathrm{H} \& \mathrm{E}$ (b) and Movat Pentachrome stain (c)
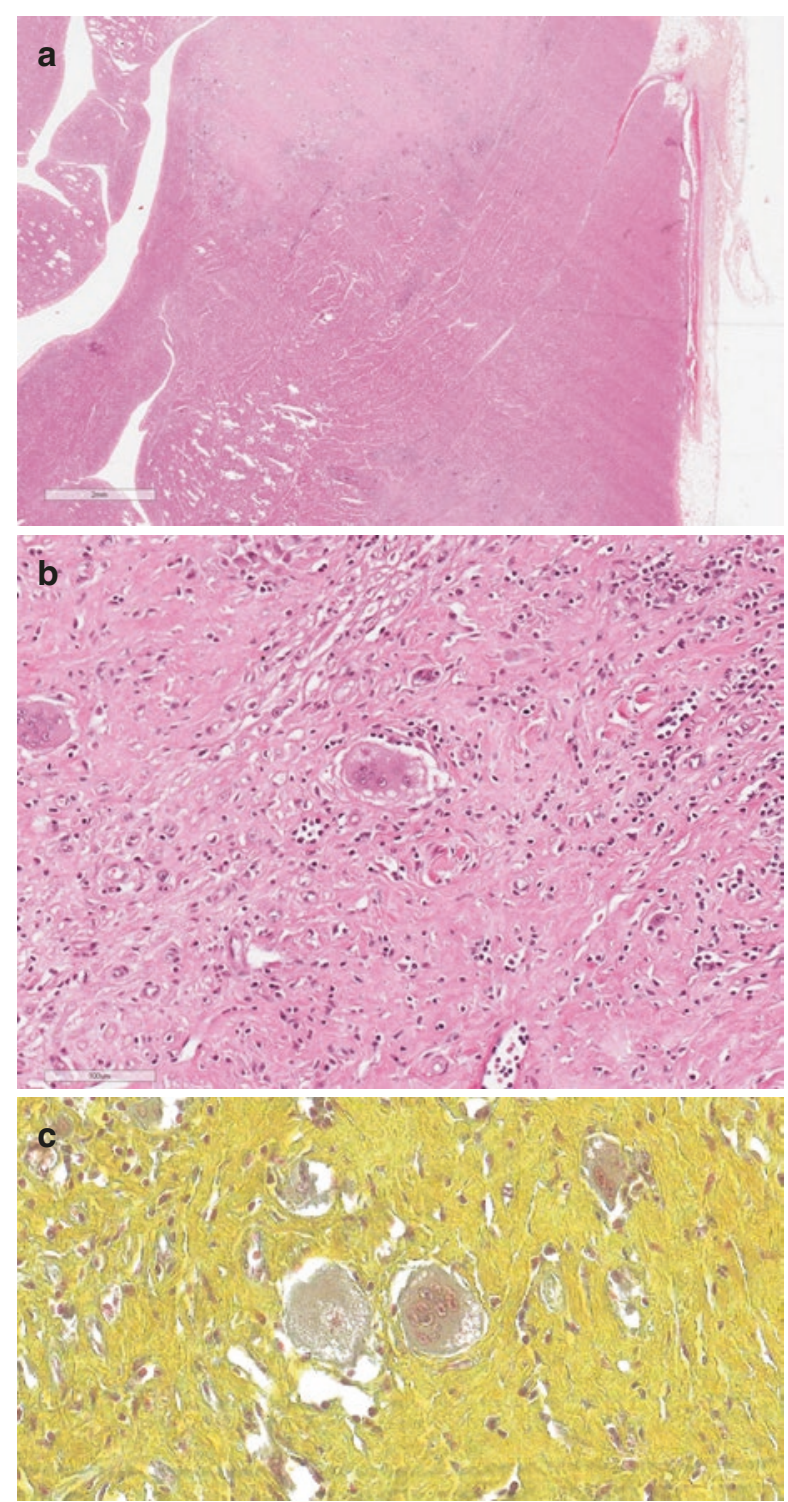

non-caseating epithelioid cell Blau granuloma. Blau syndrome is caused by mutations in the Caspase Recruitment Domain Gene 15 (CARD15 or NOD1) $(\mathrm{MIM} * 605956)$ on chromosome $16 \mathrm{q} 12.1$ [125]. The mutations are systematically collected in the international Infevers Registry [fmf.igh.cnrs.fr/infevers] [139]. Blau syndrome is allelic to early-onset sarcoidosis (EOS) [140, 141]. The diagnosis is usually suspected in the clinical context of rheumatology or dermatology or ophthalmology issues. It is unusual for patients to manifest cardiac involvement at onset. Cardiologists are more likely to be involved in the clinical management of patients diagnosed with the disease [126]. Myocarditis is not specifically mentioned 
in the complex phenotype of the disease, but pericarditis is a known possible complication and myocardial involvement and cardiac infiltration have been reported in early-onset sarcoidosis associated with CARD15 mutations [140, 141].

\subsubsection{Non-monogenic Sarcoidosis: Candidate Genes, Familial Aggregation, and Susceptibility}

Outside of Blau syndrome and EOS, sarcoidosis is usually considered an autoimmune disease with possible family susceptibility in a way that does not conform to a classic Mendelian mode of inheritance [142, 143]. The susceptibility loci and the genes identified to date are summarized in Table 4.5. SNPs in major histocompatibility complex HLA-DRA and BTNL2 genes have been associated with susceptibility to sarcoidosis. A recent multi-population study demonstrates that at least a part of these associations are $H L A-D R B 1$ independent (unrelated with linkage disequilibrium) and shared across ancestral origins. The variants that were independent of $H L A-D R B 1$ associations acted as e-quantitative trait loci for HLA$D R B 1$ and/or -DRB5, suggesting a role in regulating gene expression [144]. The $B T N L 2$ gene variant G16071A seems to be a predisposing factor for sarcoidosis except in Caucasian postmenopausal women with sarcoid uveitis in whom the GG genotype prevails [145]. Other loci associated with genetic susceptibility of sarcoidosis are pending and many candidate genes are reported but not yet confirmed (ACE, ADAM33, ANXA11, BTNL2, NOD2, CCDC88B, CCR2, GREM1, HLADRB1, IL23R, NOTCH4, C6ORF67, OS9, PRDX5, SLC11A1, TGFB1, TLR9, and TNFA) [146-149]. Genes influencing clinical presentation of sarcoidosis are likely to be different from those that underlie disease susceptibility. To date, no genetic testing has entered the clinical diagnostic path of sarcoidosis. Wholeexome sequencing studies identified rare genetic variations in families with pulmonary sarcoidosis [150]. The family-based exome sequencing study identified 40 plausible functional rare genetic variants among German families. The findings highlighted the calcium ion-related biological activities and immune responsive genes with possible involvement in pathways of immune/inflammatory response regulation, leukocyte proliferation, and defense response to bacteria, among the major mechanisms. The KEGG pathway mapping analysis indicated inflammatory bowel disease as most relevant. The complexity of the phenotype (severity, chronicity, clinical course) and the overlapping of concurrent lung disease partly explain the difficulties encountered in the studies that investigate the genetic basis of sarcoidosis [150].

\subsubsection{Familial Genetic Risk: Clinical Evaluation}

On a clinical level, it is useful to be aware of the risk of recurrence of sarcoidosis in relatives of affected patients. The ACCESS study (A Case Controlled Etiologic Sarcoidosis Study) demonstrated that first-degree relatives of patients with sarcoidosis have a five times higher relative risk of developing sarcoidosis than control subjects [151-153]. A more recent study (Swedish National Patient Register using International Classification of Diseases codes, 1964-2013) confirmed that 
having at least one first-degree relative with sarcoidosis is associated with a 3.7fold increase in the risk of sarcoidosis [154]. The relative risk increases in those with two or more relatives (relative risk 4.7) and in Löfgren's syndrome (relative risk 4.1). The percentage of heritability was 39\% (95\% CI 12-65\%). Therefore, having a relative with sarcoidosis is a strong risk factor for the disease. In clinical practice, the family history (uveitis and lung diseases in particular) should be explored with the aim of verifying whether there are other family members diagnosed with sarcoidosis [155]. Instead, in the Japanese population in which sarcoidosis is particularly frequent, the occurrence of cardiac sarcoidosis in female patients is associated with the presence of $H L A-D Q B 1 * 0601$ and the allele TNFA2 $[156,157]$. Loci formally listed in the OMIM catalogue are described in Table 4.5 $[155,158-161]$ and genetic variants investigated in sarcoidosis are reported in Table 4.6.

\subsubsection{Giant Cell Myocarditis and Genetics}

Giant cell myocarditis (GCM) is a rare and potentially fatal illness of unknown etiology characterized by myocardial inflammation with multinucleated giant cells and myocyte necrosis $[162,163]$. GCM is currently considered a "multifactorial disease triggered by different causes" [164-187]. Etiologic hypotheses include systemic autoimmune diseases [164-168], drug toxicity [169], infections [170-172], and complex combination of autoimmunity, infections and drug toxicity [173]. Infections reported in GCM include coxsackie B2 virus [170], parvovirus B19 [171], HCMV [172] and HIV1 infection [173-184]. In most cases, GCM is an isolated entity, while in about one-fifth of cases GCM occurs in association with autoimmune/immune-mediated diseases (Table 4.7), infections, drug toxicity, or syndromes such as immune reconstitution inflammatory syndrome (IRIS) in patients undergoing highly active antiretroviral therapy (HAART) against human immunodeficiency virus type 1 (HIV-1) [173, 184, 185] or even in patients taking common medications such as amoxicillin [183]. To date, the autoimmune/ immune-mediated hypothesis is the most accredited pathogenic theory supported both by the aforementioned associations with systemic autoimmune diseases (Table 4.7) and by the partial remission of GCM in patients treated with immunosuppression as well as by the non-aggressive occurrence (10-50\%) of the disease during immunosuppression treatment in transplanted patients $[186,187]$.

Table 4.5 Genetic susceptibility in sarcoidosis: loci formally included in OMIM catalogue

\begin{tabular}{l|l|l|l}
\hline $\begin{array}{l}\text { Susceptibility } \\
\text { loci }\end{array}$ & Mapping & Association with variants in: & Ref \\
\hline SS1 & $6 \mathrm{p} 21.3$ & HLA-DRB1 (HLA-DRB1 $* 03)$ & {$[155,157]$} \\
\hline SS2 & $6 \mathrm{p} 21.3$ & $\begin{array}{l}\text { BTNL2 (butyrophilin-like protein, major } \\
\text { histocompatibility complex class II-associated BTL II) }\end{array}$ & {$[159]$} \\
\hline SS3 & $10 \mathrm{q} 22-\mathrm{q} 23$ & ANXA11 (Annexin XI) & {$[160,161]$} \\
\hline
\end{tabular}


Table 4.6 Systemic sarcoidosis: familial aggregation and genetic predisposition

\begin{tabular}{|c|c|c|}
\hline \multicolumn{3}{|l|}{ Family studies } \\
\hline Series & Relatives & Risk compared with the general population \\
\hline \multirow{2}{*}{$\begin{array}{l}210 \text { twin } \\
\text { pairs }\end{array}$} & Twins, monozygotic & 80 -fold \\
\hline & Twins, dizygotic & 7-fold \\
\hline $\begin{array}{l}\text { ACCESS }(A \\
\text { Case-Control } \\
\text { Etiologic } \\
\text { Study in } \\
\text { Sarcoidosis) }\end{array}$ & $\begin{array}{l}\text { First or second } \\
\text { degree relative of a } \\
\text { patient with } \\
\text { sarcoidosis }\end{array}$ & 4.7-fold \\
\hline \multicolumn{3}{|c|}{ Genetic studies } \\
\hline $\begin{array}{l}\text { Genetic } \\
\text { association }\end{array}$ & $\begin{array}{l}\text { Chromosome } 6 \text {, } \\
\text { MHC genes }\end{array}$ & $\begin{array}{l}\text { - Acute sarcoidosis: HLA-DRB } 1 * 0301 \\
\text { - Remitting disease: HLA-DQB } 1 * 0201-\mathrm{DRB} 1 * 0301 \\
\text { - Chronic active disease: DQB } 1 * 0602-\mathrm{DRB} 1 * 150101 \\
\text { - Extra-pulmonary manifestations: HLA-DRB } 1 * 11\end{array}$ \\
\hline $\begin{array}{l}\text { Candidate } \\
\text { genes }\end{array}$ & $\begin{array}{l}\text { Case-control studies } \\
\text { and family-based } \\
\text { studies }\end{array}$ & $\begin{array}{l}\text { - Variation of TNF production: TNFA1/TNFA2; } \\
\text { rs1800629 } \\
\text { - Chronic sarcoidosis: IL23R: rs11209026 (Arg381Gln) } \\
\text { - Sarcoidosis and uveitis: IL23R: rs11209026 } \\
\text { (Arg381Gln) }\end{array}$ \\
\hline GWAS & $\begin{array}{l}\text { Susceptibility loci } \\
\text { and candidate genes }\end{array}$ & $\begin{array}{l}\text { - Butyrophilin-like } 2 \text { (BTNL2) gene: rs2076530 A } \\
\text { - Annexin A11 (ANXA11) gene: rs1049550 } \\
\text { - Ras-related protein Rab-23 (RAB23): rs1040461 } \\
\text { - Osteosarcoma amplified 9 (OS9): rs1050045 } \\
\text { - Coiled-coil domain containing 88B (CCDC88B) } \\
\text { - Peroxiredoxin 5 (PRDX5) gene } \\
\text { - Neurogenic locus notch homolog protein } 4 \\
\text { (NOTCH4) gene region: SNP rs715299 }\end{array}$ \\
\hline $\begin{array}{l}\text { Gene- } \\
\text { environment } \\
\text { interactions }\end{array}$ & $\begin{array}{l}1101 \text { patients with } \\
\text { extrapulmonary } \\
\text { sarcoidosis and } \\
\text { exposed to } \\
\text { insecticide, molds, } \\
\text { and musty odors }\end{array}$ & HLADRB $1 *$ \\
\hline
\end{tabular}

Table 4.7 Giant cell myocarditis in inflammatory autoimmune diseases

\begin{tabular}{l|l}
\hline Disease & References \\
\hline $\begin{array}{l}\text { Inflammatory bowel disease, both Crohn's disease (CD) and ulcerative colitis } \\
\text { (UC); drug reaction is a possible trigger }\end{array}$ & {$[174-176]$} \\
\hline Spondyloarthropathy & {$[177]$} \\
\hline Thymoma, myasthenia gravis & {$[168,178]$} \\
\hline Vasculitis & {$[179]$} \\
\hline Orbital myositis, vitiligo & {$[180]$} \\
\hline Autoimmune hepatitis & {$[164]$} \\
\hline Systemic lupus erythematosus & {$[181]$} \\
\hline Sjogren's syndrome & {$[182]$} \\
\hline $\begin{array}{l}\text { Immune reconstitution inflammatory syndrome (IRIS) that may occur in patients } \\
\text { undergoing highly active antiretroviral therapy (HAART) against human } \\
\text { immunodeficiency virus type 1 (HIV-1) }\end{array}$ & {$[185]$} \\
\hline
\end{tabular}


Clinical manifestations of GCM are variable. Most patients present with cardiogenic shock or acute heart failure, requiring mechanical circulatory support. However, conduction disease such as atrio-ventricular nodal or infra-nodal heart block or atrial or ventricular arrhythmias can be the first manifestation. The rare "atrial variant" is characterized by atrial fibrillation and severe atrial dilation but preserved ventricular function [188, 189]. A precise diagnosis of GCM is established only when typical pathologic features are demonstrated on EMB or surgical samples [190] (Fig. 4.4). The inflammatory infiltrate is constituted by CD8-positive lymphocytes, eosinophils, and multinucleated giant cells; myocytes show damage and necrosis $[162,163]$. The origin of giant cells, from myocytes and/or histiocytes, remains a matter of investigation. Differential diagnosis between GCM and cardiac sarcoidosis relies on pathologic features (non-caseating epithelioid granulomas with CD68-positive giant cells in sarcoidosis) and is supported by the different T-cell subsets, CD4+ in sarcoidosis and CD8+ in GCM. GCM carries a poor prognosis, with a median survival of 5.5 months from the onset of symptoms; up to $90 \%$ patients either die or require cardiac

Fig. 4.4 The figure shows the EMB done in a 42-year-old patient with fulminant clinical manifestation of giant cell myocarditis. Death occurred 52 hours after admission to the emergency room, despite ventricular support, including medications and ECMO. (a) H\&E; (b) Anti-CD68 immunostain showing specific immunereaction of giant cells. Green arrows indicate the giant cells in both panels

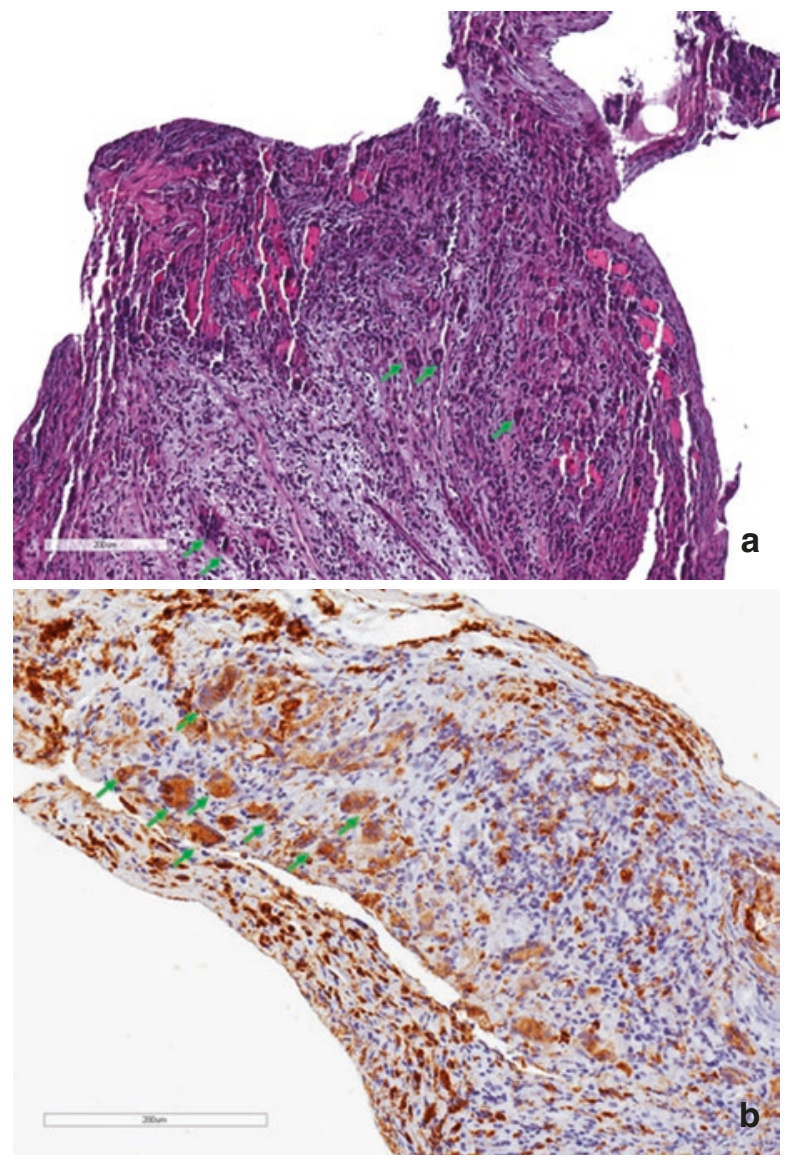


transplantation. Data on management, including medications and mechanical circulatory support for bridge to recovery or to transplantation, are given in the dedicated chapter of this book.

The occurrence of GCM in Mendelian diseases is either underreported or unexplored or anecdotal and extremely rare. Myocarditis and giant cell hepatitis have been diagnosed in a patient with spinal muscular atrophy with respiratory distress (SMARD1) that was genetically caused by a nonsense mutation in the immunoglobulin-mu-binding protein 2, IGHMBP2 disease gene. Mutations in this gene typically cause the autosomal recessive Charcot-Marie-Tooth disease, axonal, type $2 \mathrm{~S}$, and the distal hereditary motor neuronopathy type IV. This evidence does not causally link GCM with the genetic defect but rather represents a possible complication of the disease [191].

The association between GCM and myasthenia gravis (MG) and thymoma warrants special mention for two reasons: (1) the fair number of reports of GCM in patients with myasthenia gravis and (2) the association of giant cell polymyositis and myocarditis with myasthenia gravis and thymoma [168, 178, 192-195] and the possible responsiveness of myositis to novel biological drugs such as rituximab when steroids, acetylcholinesterase inhibitors, and immunosuppressive agents fail [193]. Cardiomyositis and subclinical cardiac dysfunction have been described in patients with thymoma and late-onset myasthenia gravis [192, 193].

To date, gene expression studies have not identified disease genes but rather have contributed to unraveling some pathophysiologic mechanisms of disease. Cardiac gene expression profiling has revealed upregulation of genes involved in the T-cell immune response, with the majority of upregulated genes involved in T-cell activation of the Th1 subset [196]. Plakoglobin expression was reduced in GCM and cardiac sarcoidosis as well as in ARVC, but not in lymphocytic myocarditis. A redistribution of plakoglobin from intercellular junctions to intracellular location was attributed to the mediation of IL-17 and TNF-alpha; both are considered to be mediators of granulomatous myocarditis [197].

\subsubsection{Hypereosinophilic Syndromes (HES) and Myocarditis}

Eosinophils are involved in host immune response to infection, cancer surveillance, and maintenance of other immune cells $[198,199]$. The normal range of circulating eosinophils is $3-5 \%$, which corresponds to an absolute count of $350-500 / \mathrm{mm}^{3}$ [198]. Eosinophilia (hypereosinophilia) refers to an increased absolute eosinophilic count in peripheral blood and is graded as mild (from upper normal limit to 1500/ $\left.\mathrm{mm}^{3}\right)$, moderate $\left(1500-5000 / \mathrm{mm}^{3}\right)$, and severe $\left(>5000 / \mathrm{mm}^{3}\right)$ [200]. Eosinophilia encompasses a broad range of disorders including hematologic eosinophilia (clonal, neoplastic, primary, $\mathrm{HE}_{\mathrm{N}}$ ), non-hematologic (secondary or reactive $\mathrm{HE}_{\mathrm{R}}$ ), eosinophilic diseases of unknown significance $\left(\mathrm{HE}_{\mathrm{US}}\right)$, and familial diseases $\left(\mathrm{HE}_{\mathrm{F}}\right)$ (Table 4.8). Organ damage may occur in each of these forms [201]. The heart is either the major or solely involved organ or is potentially involved in systemic diseases. Diagnostic criteria of HES [201] were modified in 2006 when the definition 
Table 4.8 Classification of HE eosinophilic syndromes

\begin{tabular}{|c|c|c|}
\hline Class & Abbreviation & Pathogenesis/definition \\
\hline $\begin{array}{l}\text { Hereditary } \\
\text { (familial, FA) HE }\end{array}$ & $\mathrm{HE}_{\mathrm{FA}}$ & $\begin{array}{l}\text { Pathogenesis unknown; familial clustering; absence of } \\
\text { hereditary immunodeficiency; and absence of a reactive } \\
\text { or neoplastic condition/disorder underlying HE }\end{array}$ \\
\hline $\begin{array}{l}\text { HE of } \\
\text { undetermined } \\
\text { significance (US) }\end{array}$ & $\mathrm{HE}_{\mathrm{US}}$ & $\begin{array}{l}\text { No underlying cause of } \mathrm{HE} \text {, no family history, no } \\
\text { evidence of a reactive or neoplastic condition/disorder } \\
\text { underlying } \mathrm{HE} \text {, and no end-organ damage attributable to } \\
\text { HE }\end{array}$ \\
\hline $\begin{array}{l}\text { Primary (clonal/ } \\
\text { neoplastic) (N) } \mathrm{HE}^{\mathrm{a}}\end{array}$ & $\mathrm{HE}_{\mathrm{N}}$ & $\begin{array}{l}\text { Underlying stem cell, myeloid, or eosinophilic neoplasm, } \\
\text { as classified by WHO criteria; eosinophils considered } \\
\text { neoplastic cells }{ }^{\text {b }}\end{array}$ \\
\hline $\begin{array}{l}\text { Secondary } \\
\text { (reactive) } \mathrm{HE}^{\mathrm{a}}\end{array}$ & $\mathrm{HE}_{\mathrm{R}}$ & $\begin{array}{l}\text { Underlying condition/disease in which eosinophils are } \\
\text { considered nonclonal cells } \text {; HE considered cytokine } \\
\text { driven in most cases }^{\mathrm{c}}\end{array}$ \\
\hline
\end{tabular}

${ }^{a} \mathrm{HEN}$ and HER should guide further diagnostic evaluations but cannot serve as final diagnoses bProven clonality: a myeloid or stem cell neoplasm typically manifesting with clonal HE; typical molecular defect is demonstrable (e.g., PDGFR or FGFR mutations or BCR/ABL1); eosinophilia should be considered clonal

'In a group of patients, HER might be caused/triggered by other as yet unknown processes because no increase in eosinophilopoietic cytokine levels can be documented

was expanded to include other previously distinct diseases associated with eosinophilia [eosinophilic granulomatosis with polyangiitis (EGPA), formerly known as Churg-Strauss syndrome, chronic eosinophilic pneumonia, and eosinophilic gastrointestinal disorders (EGID)] [200-202]. In 2010, the 6-month diagnostic period was substituted with the criterion of elevation of the absolute eosinophilic count $>1500$ / $\mathrm{mm}^{3}$ on at least two occasions [203]; it was recommended that the diagnosis had to be formulated in patients with "tissue eosinophilia and marked peripheral eosinophilia." The definition of HES was also expanded in order to include molecular evidence of end-organ damage [203]. HES has an age-adjusted prevalence of approximately 0.036 per 100,000 wherein the estimates are based on the ICDO (International Classification of Disease for Oncology Version 3), coding 9964/3 (HES including chronic eosinophilic leukemia), and the SEER database (Surveillance, Epidemiology, and End Results) [204].

\subsubsection{Somatic Mutations}

HES with somatic genetic mutation PDGFRA/B-FGFR1 fusion accounts for a minority of cases (median $=23 \%$, range $3-56 \%$ ) [205]. In developing countries, FIP1L1-PDGFRA fusion occurs in approximately 10-20\% of patients with idiopathic hypereosinophilia [205, 206], usually young adults/adults and, less commonly, children and elderly [207-210]. Most patients with FIP1L1-PDGFRA fusion or myeloproliferative variants are male [205, 211, 212], while other eosinophilia subtypes do not show gender differences. Other rearrangements such as BCR/ABL1 are far less common than FIP1L1-PDGFRA. 


\subsubsection{HES: The Clinical Phenotype}

The clinical presentation of HES is heterogeneous and nonspecific (weakness, fatigue, dyspnea, myalgias, angioedema, rash, fever, rhinitis, and diarrhea) [213]. Patients demonstrate leukocytosis (e.g., $20,000-30,000 / \mathrm{mm}^{3}$ or higher) with eosinophilia in the range of 30-70\%, neutrophilia, basophilia, myeloid immaturity, and both mature and immature eosinophils with varying degrees of dysplasia [214]. Anemia occurs in more than $50 \%$ of patients; thrombocytopenia, bone marrow eosinophilia with Charcot-Leyden crystals, and possible increased blasts and marrow fibrosis can also recur [198, 202]. Skin is the most commonly affected tissue (about $70 \%$ of patients), followed by lung and gastrointestinal manifestations in $40 \%$ and $30 \%$ of cases, respectively.

\subsubsection{Eosinophilic Disease: The Cardiac Phenotype}

Cardiac involvement occurs in $20 \%$ of patients $[214,215]$ and affects the myocardium, endocardium, and valves. The release of toxic mediators by interstitial eosinophils is associated with heart failure. Endocardial infiltration causes mural thrombi with increased embolic risk. Late phases are characterized by endocardial fibrosis manifesting with restrictive physiology. Valve regurgitation occurs when mural endocardial thrombosis and fibrosis involve mitral or tricuspid valve leaflets [214, 215]. Cardiac involvement is a major cause of morbidity and mortality in HES [216-219]. The disease course is divided into three stages: (1) an acute necrotic stage, (2) a thrombotic stage, and (3) a fibrotic stage. The early, acute necrotic stage is characterized by eosinophilic and lymphocytic infiltration; eosinophils undergo degranulation in the myocardial interstitium, releasing biologically active factors that cause myocyte injury (Fig. 4.5). In the thrombotic stage, mural thrombi stratify on the endocardium. Endocardial thrombophilia is likely promoted by the release of antifibrinolytic mediators such as PAI-2 and thrombomodulin-eosinophilic proteins that impair the anticoagulant property of the endocardial cells [209]. Thrombi most commonly involve the ventricular apex and further extend to subvalvular regions

Fig. 4.5 Acute

eosinophilic myocarditis in a patient with $\mathrm{HE}$ without known triggers/toxic substances. The FIP1L1PDGFRA rearrangements tested negative. Full clinical recovery occurred in 4 weeks after steroid treatment

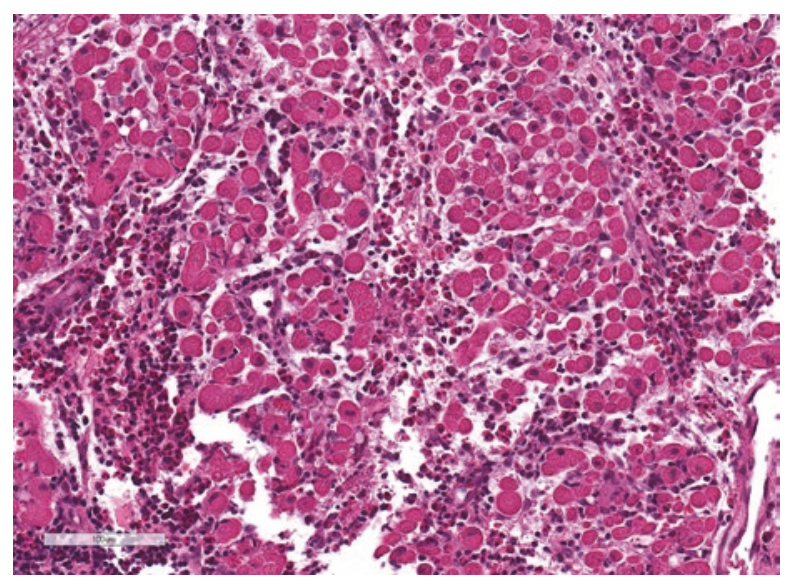


and, occasionally, to atria. In the scarring (fibrotic) stage, both ventricles and subvalvular structures of the atrio-ventricular valves are involved. The functional phenotype is typically restrictive, as in endomyocardial fibrosis [217, 218].

\subsubsection{EGPA (formerly Churg-Strauss Syndrome): Familial Clustering and Genetics}

EGPA is a systemic necrotizing vasculitis that affects small-to-medium-sized vessels [202]. EGPA belongs to the group of antineutrophil cytoplasm antibody (ANCA)-associated vasculitis (AAV) and is characterized by blood and tissue eosinophilia and asthma, thus distinct from granulomatosis with polyangiitis (Wegener's) and microscopic polyangiitis. ANCA positivity ranges from 30 to $70 \%$ in EGPA patients but is usually less frequently observed than in other AAV. Diagnostic and management algorithms for EGPA are reported in the corresponding chapter of this book. Although repeatedly mentioned in review articles, the contribution of germline mutations to EGPA remains elusive. A few reports describe familial clustering of EGPA: a sib pair, brother and sister [220], two sisters [221], and father and son [222]. The precise cause is unknown and genetic determinants or contributors remain unexplored. However, exceptional cases of organ transplantation in identical twins and different reactions to the same medication seem to exclude a genetic basis or predisposition to EGPA. One is a pair of twins in which one affected by EGPA received the identical twin graft with rejection-free excellent clinical results [223]. The second example is a pair of twins, both affected by asthma and treated with the same drug (leukotriene receptor antagonists, by instance, suspected to cause EGPA): one twin developed EGPA and the other did not [224]. Nevertheless, the search for risk factors or susceptibility continues to be an object of interest. Genetic studies that investigate the group of AAV [granulomatosis with polyangiitis (Wegener's) (GPA), microscopic polyangiitis (MPA), and Churg-Strauss syndrome (CSS)] showed that the genetic variants may vary in the three groups of AAV. As an example, the PTPN22 $620 \mathrm{~W}$ allele confers susceptibility to the development of GPA but not to MPA or CSS [225]. The Lys656Asn SNP in the LEPR gene is positively associated with Wegener granulomatosis but not with CSS [226]. SNPs in the CCL26 gene (MIM*604697) that encode the chemokine Eotaxin-3 were initially described as associated with disease susceptibility and were later found not to predict the risk of disease, irrespective of the fact that serum eotaxin-3 is a sensitive and specific marker for the diagnosis of active CSS suitable for routine clinical practice [227]. Therefore, current evidence does not support a role for genetic variants in susceptibility to EGPA.

\subsection{Inherited Primary Immunodeficiency Diseases (PID): Myocarditis and VARIABLE Cardiovascular Involvement}

In PIDs, infections and inflammation are the complication and not the cause. The number of correctly diagnosed PID patients is progressively growing, with increased identification of previously unknown disease genes and availability of 
specific genetic tests. PIDs encompass a broad spectrum of inheritable disorders that are associated with increased susceptibility to infections, immune dysregulation, and malignancies [228]. PIDs are complex diseases with wide overlap (infection and/or malignancy) and immune dysregulation (auto-inflammation, auto-immunity, and/or allergy). The last classification guides the genetic and molecular diagnosis of patients with these rare diseases [228, 229]. However, the classification is complex (Table 4.9) and the extent and impact of these diseases on the cardiovascular system is far from being elucidated. Nonetheless, cardiologists are involved in the management of these patients, especially when myocarditis complicates the course of the disease. An example of PID with divergent cardiac

Table 4.9 Primary immunodeficiency syndromes (PID)

\begin{tabular}{|c|c|}
\hline PID type & Inheritance and disease genes \\
\hline $\begin{array}{l}\text { Cellular and } \\
\text { humoral immunity }\end{array}$ & $\begin{array}{l}\text { - X-linked: IL2RG } \\
\text { - Autosomal recessive JAK3, IL7RA, PTPRC, CD3D, CD3E, CD3Z, } \\
\text { CORO1A, RAG1, RAG2, ARTEMIS, PRKDC, VDj, LIG4, AK2, ADA, } \\
\text { DOCK2, CD4OLG, CD40, ICOS, CD3G, CD8A, ZAP70, TAP1, TAP2, } \\
\text { TAPBP, B2M, CIITA, RFXANK, RFX5, RFXAP, ITK, MAGT1, } \\
\text { DOCK8, RHOH, STK4, TRAC, B2M, IL21, MAP3K, CTPS1, LCK, } \\
\text { MALT1, CARD11, BCL10, IL21, IL21R, OX40, IKBKB, LRBA, CD27, } \\
\text { NIK, CTPS1, Omenn syndrome (hypomorphic mutations in RAG1, } \\
\text { RAG2, Artemis, IL7RA, RMRP, ADA, DNA Ligase IV, IL2RG, AK2) or } \\
\text { associated with DiGeorge syndrome }\end{array}$ \\
\hline $\begin{array}{l}\text { Combined } \\
\text { immunodeficiencies } \\
\text { with associated or } \\
\text { syndromic features }\end{array}$ & $\begin{array}{l}\text { - X-linked: Wiskott-Aldrich syndrome (WAS); WAS gene } \\
\text { - Autosomal recessive: WIPF1, ATM, NBS1, BLM, DNMT3B, ZBTB24, } \\
\text { PMS2, RNF168, MCM4, } \\
\text { Contiguous gene deletion in chromosome 22q11.2 or mutation of a gene } \\
\text { within this deletion region, TBX1 (DiGeorge Syndrome); CHARGE } \\
\text { Syndrome (CHD7, SEMA3E, FOXN1, RMRP, SMARCAL1, STAT3, } \\
\text { SPINK5, PGM3, DKC1, NOLA2, NOLA3, RTEL1, TERC, TERT, TINF2, } \\
\text { TPP1, DCLRE1B, PARN, TCN2, SLC46A1, MTHFD, NEMO /IKBKG, } \\
\text { IKBA (NFKIAB), ORAI1, STIM1, SP110, POLE1, TTC7A, EPG5, PNP, } \\
\text { HOIL1/RBCK1, HOIP1 (/RNF31), CCBE1, STA5B }\end{array}$ \\
\hline $\begin{array}{l}\text { Predominantly } \\
\text { antibody } \\
\text { deficiencies }\end{array}$ & $\begin{array}{l}\text { 1. } \downarrow \text { of serum immunoglobulin isotypes with decreased or absent B cells } \\
\text { - X-linked: } B K T \text {, } \\
\text { - Autosomal recessive: IGHM, IGLL1, CD79A, CD79B, BLNK, } \\
\text { PIK3R1, TCF3, }\end{array}$ \\
\hline
\end{tabular}

2. $\downarrow$ of at least two serum immunoglobulin isotypes with normal or low number of B cell

- Autosomal recessive: CD19, CD81, CD20, TNFRSF13B, TNFRSF13C, TWEAK (TNFSF12), NFKB2, TRNT1, TTC37,

3. $\downarrow$ of serum $\operatorname{IgG}$ and $\operatorname{IgA}$ with normal/elevated $\operatorname{IgM}$ and normal numbers of B cells

- Autosomal recessive: AICDA, UNG, MSH6,

4. Isotype or light chain deficiencies with generally normal numbers of B cells

- Autosomal dominant: PIK3CD, PIK3R1, CARD11

- Autosomal recessive: deletion at 14q32, Kappa constant gene, CARD11 
Table 4.9 (continued)

\begin{tabular}{|c|c|}
\hline PID type & Inheritance and disease genes \\
\hline $\begin{array}{l}\text { Diseases of immune } \\
\text { dysregulation }\end{array}$ & $\begin{array}{l}\text { 1. Familial hemophagocytic lymphohistiocytosis (FHL) syndromes } \\
\text { 1.1 FHL syndromes without hypopigmentation } \\
\text { - X-linked: SH2D1A, XIAP } \\
\text { - Autosomal recessive: PRF1, UNC13D, STX11, STXBP2. } \\
\text { 1.2 FHL syndromes with hypopigmentation } \\
\text { - Autosomal recessive: LYST, RAB27A, AP3B1, PLDN, } \\
\text { 2. T-regulatory cells genetic defects } \\
\text { - X-linked: FOXP3, } \\
\text { - Autosomal recessive: IL2RA } \\
\text { - Autosomal dominant: CTLA4 }\end{array}$ \\
\hline $\begin{array}{l}\text { Congenital defects } \\
\text { of phagocyte } \\
\text { number, function, } \\
\text { or both }\end{array}$ & $\begin{array}{l}\text { 1. Congenital neutropenias } \\
\text { - Autosomal dominant: ELANE, GFI1, } \\
\text { - Autosomal recessive: HAX1, G6PC3, VPS45, G6PT1, ROBLD3/ } \\
\text { LAMTOR2, TAZ, CPH1, C16ORF57 (USB1), JAGN1, CLPB, CSF3R, }\end{array}$ \\
\hline
\end{tabular}

2. Defects of motility

- Autosomal recessive: IRGB2, KINDLIN3, FPR1, CTSC, C/EBPE, SBDS,

- Autosomal dominant: RAC2, $A C T B$

3. Defects of respiratory burst

- X-linked: $C Y B B$

- Autosomal recessive: $C Y B A, N C F 1, N C F 2, N C F 4$,

4. Other defects:

- Autosomal dominant: GATA4, CSF2RA

Defects in intrinsic 1 . Mendelian susceptibility to mycobacterial disease (MSMD)

and innate

- X-linked: $C Y B B$

immunity

- Autosomal recessive: IL12RB1, IL12B, IFNGRI (also AD), IFNGR2, STAT1, TYK2, ISG15, RORC, TMC6, TMC8, CXCR4,

- Autosomal dominant: IRF8

2. Epidermodysplasia verruciformis

- Autosomal recessive: TMC6, TMC8, CXCR4,

3. Predisposition to severe viral infection

- Autosomal recessive: STAT1, STAT2, IRF7, CD16,

4. Herpes simplex encephalitis (HSE)

- Autosomal dominant and autosomal recessive: TLR3, TRIF,

- Autosomal dominant: TRAF3, TBK1,

- Autosomal recessive: UNC93BI

5. Predisposition to invasive fungal diseases

- Autosomal recessive: CARD9

6. Chronic mucocutaneous candidiasis (CMC)

- Autosomal dominant: IL17F, STAT1,

- Autosomal recessive: IL17RA, IL17RC, ACT1 (TRAF3IP2),

7. TLR signaling pathway deficiency

- Autosomal dominant: RPSA, APOL-I (trypanosomiasis)

- Autosomal recessive: IARK4, MYD88,

Auto-inflammatory disorders
1. Defects effecting the inflammasome

- Autosomal dominant and autosomal recessive: $M E F V$,

- Autosomal dominant: NLRP3, NLRP12, NLRP3, NLRC4, PLCG2, PLCG2, TNFRSF1A, PSTPIP1 (C2BP1), NOD2 (CARD15), CARD14, SH3BP2, COPA,

- Autosomal recessive: MVK, ADAM17, LPIN2, IL1RN, IL36RN, SLC29A3, PSMB8, 
Table 4.9 (continued)

\begin{tabular}{l|l}
\hline PID type & Inheritance and disease genes \\
\hline Complement & 1. Integral complement cascade component deficiencies \\
& - Autosomal dominant: $C 3$ \\
& - Autosomal recessive: $C 1 Q A, C 1 Q B, C 1 Q C, C 1 R, C 1 S, C 4 A, C 4 B$, \\
& $C 2, C 3, C 5, C 6, C 7, C 8 A, C 8 G, C 9, M A S P 2, F C N 3$, \\
& 2. Complement regulatory defects \\
& - X-linked: CF \\
& - Autosomal dominant and autosomal recessive: $C F H, C F H R 1-5$, \\
& - Autosomal dominant: $S E R P I N G 1, C F B, T H B D, C D 46$, \\
Phenocopies of PID & $\begin{array}{l}\text { Associated with somatic mutations } \\
\text { - TNFRSF6, KRAS, NRAS, NLRP3, } \\
\text { Associated with autoantibodies } \\
\end{array}$
\end{tabular}

phenotypes (HCM and myocarditis) seems appropriate to give the perception of the complexity of the clinical manifestations.

\subsubsection{The Omenn Syndrome (OMIM\# 603554)}

Children with Omenn Syndrome may have erythroderma, lymphadenopathy, eosinophilia, and profound immunodeficiency hepatosplenomegaly, failure to thrive, diarrhea, and alopecia; common laboratory abnormalities are eosinophilia and increased IgE, lymphocytosis, anemia, hypogammaglobulinemia, hypoproteinemia, and reduced lymphoproliferative responses to mitogens. Characteristic pathology includes thymic dysplasia, loss of B-cell-containing regions within the reticuloendothelial system, and extensive infiltrates of eosinophils and interdigitating reticular cells. The spectrum of cardiac involvement ranges from myocarditis to hypertrophic cardiomyopathy (HCM). In children with Omenn syndrome, cytomegalovirus (CMV) infections, which often run asymptomatic, can cause fatal CMV myocarditis [230]. Pathology may show pancarditis with eosinophil-rich inflammatory infiltrate in the myocardium [231]. Endomyocardial biopsy may show a mild $\mathrm{T}$ lymphocyte and histiocyte infiltrate and lack of myocyte hypertrophy [232]. Other manifestations include biventricular hypertrophy, impaired left ventricular systolic function, and severe sinus bradycardia, possibly secondary to endomyocardial disease caused by eosinophilia [233]. Successful bone marrow transplantation (BMT) has been reported in a patient with hypertrophic nonobstructive cardiomyopathy who developed BCG infection following neonatal vaccination [234].

\subsubsection{Myocarditis in Immunocompromised Patients: Humoral Immunity}

\subsubsection{Agammaglobulinemia}

Patients with X-linked agammaglobulinemia (XLA), a primary immunodeficiency caused by mutations in the gene that codes for Bruton tyrosine kinase (BTK), 
demonstrate deficient development of B lymphocytes and hypogammaglobulinemia. Infections are the most common clinical presentation (85\%), followed by a positive family history (41\%) and neutropenia (11\%). Myocardial involvement is rare. Patients commonly manifest otitis (70\%), pneumonia (62\%), sinusitis $(60 \%)$, chronic/recurrent diarrhea (23\%), conjunctivitis $(21 \%)$, pyoderma and/or cellulitis (18\%), meningitis/encephalitis (11\%), sepsis (10\%), septic arthritis (8\%), hepatitis $(6 \%)$, and osteomyelitis (3\%) [235]. BTK inhibitors are used for treatment of leukemia; these patients are exposed to high risk of pneumonia; the risk of myocarditis is unknown. However, polymorphisms in genes coding IL-6 and IL-10 and Fcg RIIa receptors (B lymphocyte growth and differentiation factors) increase susceptibility to pneumonia. In case of humoral immunodeficiency, antibody replacement therapy may be indicated [236].

\subsubsection{Hypogammaglobulinemia}

Patients with hypogammaglobulinemia, both inherited and acquired, are exposed to high risk of infections, in particular to those controlled through humoral immunity, such as picornaviridae infections. Bi-allelic mutations in LRBA (from Lipopolysaccharide-responsive and beige-like anchor protein) cause primary immunodeficiency with clinical features ranging from hypogammaglobulinemia and lymphoproliferative syndrome to inflammatory bowel disease and heterogeneous autoimmune manifestations [237]. A recent report describes the case of a 16-year-old female affected by systemic lupus erythematosus that was diagnosed 6 years before. She was admitted to hospital with chest pain and dyspnea. Her hypogammaglobulinemia was iatrogenic and secondary to rituximab treatment. The key clinical diagnosis was myocarditis caused by human parechovirus (HPeV) (Picornaviridae family of RNA viruses). The diagnosis of myocarditis was clinically suspected and confirmed with endomyocardial biopsy. IVIG therapy did not prevent encephalitis [238]. Patients, especially children, affected by hematologiconcologic disorders and solid organ malignancies and appropriately treated for their disease, may develop neutropenia and decrease of their serum immunoglobulin levels. In these patients, the risk of myocarditis (bacterial and viral) is high; as such, when presenting with signs of heart failure, myocarditis should be considered and a precise diagnosis (presence of myocarditis and cause) should be obtained because of the associated mortality, even in patients with disease remission [239].

\subsubsection{Congenital Neutropenia}

The term "congenital neutropenia" encompasses a large group of permanent and intermittent neutropenic diseases defined by severely $\left(<0.5 \times 10^{9} / \mathrm{L}\right)$ or mildly $(0.5$ and $1.5 \times 10^{9} / \mathrm{L}$ ) reduced neutrophil count. The diseases are characterized by clinical and genetic heterogeneity and may affect the pancreas, central nervous system, heart, bone, muscle, and skin. The prevention and/or control of infections, the management of associated organ dysfunction, and the prevention of leukemic transformation constitute the main treatment targets [240]. Information on cardiac involvement in the numerous and complex types of congenital neutropenia is in its 
infancy and many of these diseases have recently been characterized on the geneticmolecular level. In addition, they are very rare, clinically heterogeneous, and often burdened by early extracardiac complications that may limit their complete phenotypic expression. However, future scientific developments can broaden horizons for expanding the knowledge of the pathogenic mechanisms of cardiac infections. The heart is involved in many of these diseases. For some of them, cardiac manifestations are being characterized and classified, with two possible major phenotypes: congenital heart disease (CHD) and myocarditis/cardiomyopathy. Two examples can underscore the importance of ongoing clinical research in this area.

\subsubsection{Severe Congenital Neutropenia Type IV (SCN IV or SCN4) or G6PC3 Deficiency}

SCN4 is an autosomal recessive disease characterized by severe congenital neutropenia, intermittent thrombocytopenia, prominent superficial venous circulation, congenital heart defects [atrial septal defect (ASD) being the most common], and urogenital malformations [241]. Although most cases are syndromic, non-syndromic forms are also reported [242]. The description of the spectrum of the phenotype is expanding and definitive SCN4 phenotype/genotype has not been established thus far. The recurrent p.Gly260Arg mutation has been identified in nine different patients with ASD type 2 [241, 243-245]. Treatment with granulocyte colonystimulating factor restores the absolute neutrophil count and neutrophil functional competence. Myocarditis has not been described. However, this new field of knowledge, given the cardiovascular relevance and the possibility that SCN4 manifests with non-syndromic phenotype, must at least be known by cardiologists and reported to hematologists when these patients present with neutropenia and/or thrombocytopenia and/or associated CHD.

\subsubsection{Shwachman-Diamond Syndrome (SDS)}

SDS is an autosomal recessive disorder characterized by bone marrow failure and exocrine pancreatic dysfunction [246]. Two kinds of cardiac involvement have been described: "cardiomyopathies with heart failure (myocardial fibrosis and histopathological necrosis)" and CHD [247-249]. Recently, a case of dilated cardiomyopathy with refractory heart failure was reported in a 15-year-old girl with SDS [250]. Of 102 patients with genetically proven SDS, 12 had cardiac abnormalities: six had cardiomyopathy and six had CHD [251]. The pathologic substrates of systolic dysfunction are still unexplored, with few sporadic cases describing DCM with myocardial fibrosis. However, cardiac evaluation is also a major clinical need before and during cardiotoxic chemotherapy in case of hematopoietic stem cell transplantation (HSCT) [252]. The cardiac marker potentially predicting the progression to heart failure is circumferential strain $\varepsilon(\mathrm{cc})$ that is abnormal in $33 \%$ of cases prior to HSCT and $33 \%$ of those who had undergone HSCT in those with normal left ventricular ejection fraction [253]. 


\subsection{Auto-Inflammatory Syndromes (AIS) and Myocarditis}

\subsubsection{Introduction}

Auto-inflammatory syndromes (AIS) encompass a large group of diseases clinically characterized by recurring inflammatory manifestation with variable organ involvement and febrile episodes [254]. The classification is complex and the number of diseases and related genetic causes is continuously expanding [255, 256]. The term auto-inflammation links the phenotypes with the defects of innate immune-mediated inflammation and distinguishes the related diseases from those caused by the dysfunction of adaptive immune function, i.e., those associated with autoimmune disorders. The number of myocarditis described in auto-inflammatory disease is low. The reasons may be that myocarditis is indeed very rare, or that, in the syndromic setting in which myocarditis may occur, the involvement of other organs and systems determines the phenotype and the course of the disease, or that our limited knowledge prevents precise phenotype description of AIS with myocardial involvement. Nevertheless, myocarditis deserves to be mentioned in the context of the AIS because it can occur and because its presence and evolution can seriously alter the clinical course of these patients.

\subsubsection{Major Groups of AIS}

IL-1-mediated auto-inflammatory syndromes include familial Mediterranean fever (FMF) that is the first systemic auto-inflammatory disorder to be genetically characterized. FMF is a rare autosomal recessive disease caused by homozygous or double heterozygous mutations in the $M E F V$ gene encoding pyrin [257]. Another systemic auto-inflammatory disorder, the autosomal dominant receptor-associated periodic fever syndrome (TRAPS), was identified after the discovery of the TNFR1 gene, which encodes the extracellular domains of the $55 \mathrm{kDa}$ TNF receptor [258, 259]. Both FMF and TRAPS manifest with unexplained fevers, skin rashes, serositis, and arthralgias, in variable combinations. Myocarditis is uncommonly reported in both disorders and other IL-1-mediated auto-inflammatory syndromes [260], with pericarditis being much more common and potentially limiting the distinction of myocarditis from pericarditis.

In the IL-18-mediated auto-inflammation and susceptibility to macrophageactivation syndrome (MAS), myocarditis can be a complication of the underlying phenotype [261]. The disease gene is NLRC4 and the diagnostic marker is the high level of IL18 that results from spontaneous and induced macrophage activation and pyroptosis. However, the levels of IL18 are not routinely measured in patients with suspected myocarditis; therefore, a diagnostic marker for a very rare disease is missing in clinical practice. 
The A20 haplo-insufficiency-related syndromes are gaining attention for the new association with adult-onset Still's Disease (AOSD), a condition in which myocarditis is not uncommon. AOSD is a rare disease clinically characterized by fevers, arthritis, and skin rash. The etiology is unknown, but recent advances in the identification of the causes and characterization of the phenotypes of AIS are lending way to identifying the specific cause(s). As anticipated, A20 haplo-insufficiency (HA20) is one of the causes of AIS [262]. The A20 protein, which is encoded by the TNFAIP3 gene, is a critical inhibitor of pro-inflammatory signaling pathways and is involved in negative regulation of auto-inflammation and autoimmunity [263]. The clinical phenotypes associated with HA20 are heterogeneous, including autoimmune diseases (Behçet's disease, hereditary fever-like condition, juvenile idiopathic arthritis, systemic lupus erythematosus, and rheumatoid arthritis) and, recently, AOSD: a splice site mutation on the TNFAIP3 gene has been identified in a patient previously diagnosed with adult-onset Stills' disease (AOSD) [264]; once correctly diagnosed, the patient was successfully treated with anti-IL6 receptor biologic tocilizumab [265]. Myocarditis has been repeatedly reported in AOSD, presenting as myocarditispericarditis [265-274], with pericarditis occurring in more than 50\% of cases [265]. Coronary arteritis has also been described [272]. In most cases, the diagnosis of myocarditis was formulated on the basis of clinical, biochemical, and imaging criteria. An appropriate endomyocardial biopsy study, however, should be performed to distinguish pericarditis from myocarditis, mostly because the chronic consequences can be different, irrespective of the cause.

The interferon-mediated auto-inflammatory diseases (or type I interferonopathies or IFN-mediated auto-inflammatory diseases (IMADs)) are defined by the chronic excessive type I interferon (IFN) production [275] and include the group of Aicardi-Goutières Syndromes (AGS), in which the "cardiomyopathy" phenotype is part of the spectrum of clinical manifestations of these diseases (Table 4.10).

Table 4.10 Aicardi-Goutieres syndromes

\begin{tabular}{l|l|l|l|l|l}
\hline & $\begin{array}{l}\text { Phenotype } \\
\text { MIM } \\
\text { number }\end{array}$ & Inheritance & Chromosome & Gene/Locus & $\begin{array}{l}\text { MIM } \\
\text { number }\end{array}$ \\
\hline $\begin{array}{l}\text { Aicardi-Goutieres } \\
\text { syndrome 1 }\end{array}$ & 225750 & AD, AR & $3 \mathrm{p} 21.31$ & TREX1 & 606609 \\
\hline $\begin{array}{l}\text { Aicardi-Goutieres } \\
\text { syndrome 2 }\end{array}$ & 610181 & AR & $13 \mathrm{q} 14.3$ & RNASEH2B & 610326 \\
\hline $\begin{array}{l}\text { Aicardi-Goutieres } \\
\text { syndrome 3 }\end{array}$ & 610329 & AR & $11 \mathrm{q} 13.1$ & RNASEH2C & 610330 \\
\hline $\begin{array}{l}\text { Aicardi-Goutieres } \\
\text { syndrome 4 }\end{array}$ & 610333 & AR & $19 \mathrm{p} 13.13$ & RNASEH2A & 606034 \\
\hline $\begin{array}{l}\text { Aicardi-Goutieres } \\
\text { syndrome 5 }\end{array}$ & 612952 & AR & $20 \mathrm{q} 11.23$ & SAMHD1 & 606754 \\
\hline $\begin{array}{l}\text { Aicardi-Goutieres } \\
\text { syndrome 6 }\end{array}$ & 615010 & AR & $1 \mathrm{q} 21.3$ & ADAR & 146920 \\
\hline $\begin{array}{l}\text { Aicardi-Goutieres } \\
\text { syndrome 7 }\end{array}$ & 615846 & AD & $2 \mathrm{q} 24.2$ & IFIH1 & 606951 \\
\hline
\end{tabular}


AGS are characterized by hypothyroidism, chilblains, glaucoma, cardiomyopathy, intracerebral vasculitis, peripheral neuropathy, bowel inflammation, and systemic lupus erythematosus [276]. AGSs (types 1-7) are auto-inflammatory diseases caused by mutations of genes involved in nucleic acid metabolism/signaling (TREX1, RNASEH2A, RNASEH2B, RNASEH2C, SAMHD1, ADAR, or IFIH1) and can manifest with in utero disease onset or with postnatal presentation, usually within the first year of life, with subacute encephalopathy (Table 4.10) [277]. The pathology of affected hearts is still largely unexplored. Cardiac involvement has been described as infantile-onset hypertrophic cardiomyopathy with hypothyroidism and demyelinating peripheral neuropathy. Whether the pathologic substrate of the cardiomyopathy has inflammatory origin is still unknown [278]. The absence of Trex1 (TREX1 is one of the known disease genes causing AGS) in mice causes myocarditis [278]. The enzyme degrades endogenous retro-elements, thus linking them to autoimmune disease. In the Trex1-null mouse, an FDA-approved drug that inhibits reverse transcriptase can improve the myocarditis, indicating that retroelements (RE) play a role in this hereditary form of autoimmunity and that administration of RE inhibitors might ameliorate AGS [279]. The possible association of mutations in other genes associated with $A G S$ and myocarditis is still unexplored. However, mutations in IFIH1 cause Singleton-Merten syndrome 1 (SMS1), which is allelic at the same locus of AGS7 and may manifest with cardiomegaly, heart failure, and conduction disease. The syndrome (aortic calcification, dental anomalies, osteopenia and acro-osteolysis, glaucoma, psoriasis, muscle weakness, joint laxity and abnormal facies traits with broad forehead, high anterior hairline, smooth philtrum, and thin upper vermilion border) is unlikely to escape clinical detection [280]. In addition, very recent experimental studies explored the involvement of adenosine deaminases acting on RNA 1 (ADARl) (AGS6) in inflammatory diseases, cancer, and host defenses against viral infections. ADARs are enzymes that regulate RNA metabolism through post-transcriptional mechanisms. In particular, the complex ADAR1p150/DICER promotes the expression of miRNA-222 that is highly expressed in cardiac myocytes in viral myocarditis. In cultured cells, miR222 suppresses PTEN expression. These preliminary experimental studies suggest that ADAR1p150 could play a role in gene expression in viral myocarditis [281]. The cardiovascular impact of type I interferonopathies such as AGS (TREX1 and IFIH1 in particular) could go beyond possible myocardial inflammation and expand to primary pulmonary hypertension [282] as well as to the risk of coronary artery disease [283].

\subsection{Conclusions}

Based on the current state of knowledge on myocarditis, we can say that infectious myocarditis is not in fact a genetic disease, as in the absence of an infectious pathogen, there is no myocarditis. However, a rigorous attempt is being made to establish who and why, with equal exposure to the same pathogen, develops myocarditis. Individual gene variants are candidates to play a role in both disease susceptibility/ 
predisposition and contribute to the severity of phenotypes and outcomes observed in different patients with myocardial infections caused by the same pathogens.

Non-infectious myocarditis, excluding exogenous toxic exposures, may have a hereditary basis or be strongly influenced by genetic factors. It is clinically difficult to distinguish acquired and inherited forms, further because the hereditary forms are often passed as recessive traits. Finally, inherited diseases in immunodeficiency syndromes and auto-inflammatory diseases can have overlapping causes and phenotypes in which myocarditis may occur. These are often syndromic disorders. Many of them have been identified only recently, and the number of reported and proven cases is limited to a few case reports or small clinical series. This clinical area is also continuously expanding, and in the short term, we expect radical changes in our knowledge and understanding of the mechanisms and causes of myocarditis. A critical point remains unsolved: true myocarditis is that diagnosed on tissue biopsy, at least until molecular imaging techniques are readily and routinely available, to demonstrate not the myocardial edema, but the inflammatory interstitial cells. Until then, we can accept a scientific literature that is based on non-biopsy diagnoses, but we retain the belief that, in the absence of pathological evidence, not all diagnoses are correct. The cardiologist should lead the diagnostic work-up of these diseases as well as the clinical management of these patients.

\section{References}

1. Arbustini E, Agozzino M, Favalli V, Pinney S, Narula J. Myocarditis. In: Fuster V, Harrington RA, Narula J, Eapen ZJ, editors. Hurst's the heart, Chapter 63. 14th ed. New York: McGrawHill; 2017.

2. Bondue A, Arbustini E, Bianco A, et al. Complex roads from genotype to phenotype in dilated cardiomyopathy: scientific update from the Working Group of Myocardial Function of the European Society of Cardiology. Cardiovasc Res. 2018;114(10):1287-303.

3. Heidt T, Courties G, Dutta P, et al. Differential contribution of monocytes to heart macrophages in steady-state and after myocardial infarction. Circ Res. 2014;115:284-95.

4. Pinto AR, Paolicelli R, Salimova E, et al. An abundant tissue macrophage population in the adult murine heart with a distinct alternatively-activated macrophage profile. PLoS One. 2012;7:e36814.

5. Epelman S, Lavine KJ, Beaudin AE, et al. Embryonic and adult-derived resident cardiac macrophages are maintained through distinct mechanisms at steady state and during inflammation. Immunity. 2014;40:91-104.

6. Molawi K, Wolf Y, Kandalla PK, et al. Progressive replacement of embryo-derived cardiac macrophages with age. J Exp Med. 2014;211:2151-8.

7. Gomez I, Duval V, Silvestre JS. Cardiomyocytes and macrophages discourse on the method to govern cardiac repair. Front Cardiovasc Med. 2018;5:134.

8. Monnerat G, Alarcón ML, Vasconcellos LR, et al. Macrophage-dependent IL-1 $\beta$ production induces cardiac arrhythmias in diabetic mice. Nat Commun. 2016;7:13344.

9. Fung G, Luo H, Qiu Y, Yang D, McManus B. Myocarditis. Circ Res. 2016;118:496-514.

10. Stanaway JD, Roth G. The burden of Chagas disease: estimates and challenges. Glob Heart. 2015;10:139-44.

11. Chomel B. Lyme disease. Rev Sci Tech. 2015;34:569-76.

12. Caforio ALP, Pankuweit S, Arbustini E, European Society of Cardiology Working Group on Myocardial and Pericardial Diseases, et al. Current state of knowledge on aetiology, 
diagnosis, management, and therapy of myocarditis: a position statement of the European Society of Cardiology Working Group on Myocardial and Pericardial Diseases. Eur Heart J. 2013;34(33):2636-48.

13. Caforio ALP, Adler Y, Agostini C, et al. Diagnosis and management of myocardial involvement in systemic immune-mediated diseases: a position statement of the European Society of Cardiology Working Group on Myocardial and Pericardial Disease. Eur Heart J. 2017;38(35):2649-62.

14. Banoo S, Bell D, Bossuyt P, TDR Diagnostics Evaluation Expert Panel, et al. Evaluation of diagnostic tests for infectious diseases: general principles. Nat Rev Microbiol. 2010;8:S17-29.

15. Rostoff P, Nessler B, Pikul P, Golinska-Grzybala K, Miszalski-Jamka T, Nessler J. Fulminant adrenergic myocarditis complicated by pulmonary edema, cardiogenic shock and cardiac arrest. Am J Emerg Med. 2018;36(2):344.e1-4.

16. Bissel SJ, Winkler CC, DelTondo J, Wang G, Williams K, Wiley CA. Coxsackievirus B4 myocarditis and meningoencephalitis in newborn twins. Neuropathology. 2014;34(5):429-37.

17. Amdani SM, Kim HS, Orvedahl A, John AO, Said A, Simpson K. Successful treatment of fulminant neonatal enteroviral myocarditis in monochorionic diamniotic twins with cardiopulmonary support, intravenous immunoglobulin and pocapavir. BMJ Case Rep. 2018;2018:bcr-2017-224133.

18. Cho HJ, Ma JS. Left ventricular non-compaction progression to dilated cardiomyopathy following acute myocarditis in an early infant twin. Minerva Pediatr. 2015;67(2):199-202.

19. Bajanowski T, Rossi L, Biondo B, et al. Prolonged QT interval and sudden infant deathDOUBLEHYPHENreport of two cases. Forensic Sci Int. 2001;115(1-2):147-53.

20. Cognet T, Lairez O, Marchal P, Roncalli J, Galinier M. A family history of dilated cardiomyopathy induced by viral myocarditis. Case Rep Cardiol. 2012;2012:204371.

21. Sharma K, Orbai AM, Desai D, et al. Brief report: antisynthetase syndrome-associated myocarditis. J Card Fail. 2014;20(12):939-45.

22. Tsirpanlis G, Moustakas G, Sakka E, et al. Catastrophic antiphospholipid syndrome in a 14-year-old child. Pediatr Nephrol. 2005;20(4):519-21.

23. Roubille F, Cayla G, Gahide G, Mourad G, Macia JC. Acute myocarditis and tumor necrosis factor receptor-associated periodic (TRAP) syndrome: first case described and discussion. Eur J Intern Med. 2009;20(2):e25-6.

24. Cunha-Neto E, Chevillard C. Chagas disease cardiomyopathy: immunopathology and genetics. Mediat Inflamm. 2014;2014:683230.

25. Hintenberger R, Falkinger A, Danninger K, Pieringer H. Cardiovascular disease in patients with autoinflammatory syndromes. Rheumatol Int. 2018;38(1):37-50.

26. Bousfiha A, Jeddane L, Al-Herz W, et al. The 2015 IUIS phenotypic classification for primary immunodeficiencies. J Clin Immunol. 2015;35(8):727-38.

27. Casanova JL. Human genetic basis of interindividual variability in the course of infection. Proc Natl Acad Sci U S A. 2015;112(51):E7118-27.

28. Casanova JL. Severe infectious diseases of childhood as monogenic inborn errors of immunity. Proc Natl Acad Sci U S A. 2015;112(51):E7128-37.

29. Haerynck F, Holland SM, Rosenzweig SD, et al. Disseminated Mycobacterium avium infection in a patient with a novel mutation in the interleukin-12 receptor-beta1 chain. J Pediatr. 2008;153(5):721-2.

30. Gorbea C, Makar KA, Pauschinger M, et al. A role for toll-like receptor 3 variants in host susceptibility to enteroviral myocarditis and dilated cardiomyopathy. J Biol Chem. 2010;285(30):23208-23.

31. Cannatà A, Artico J, Gentile P, Merlo M, Sinagra G. Myocarditis evolving in cardiomyopathy: when genetics and offending causes work together. Eur Heart J Suppl. 2019;21(Suppl B):B90-5.

32. Belkaya S, Kontorovich AR, Byun M, et al. Autosomal recessive cardiomyopathy presenting as acute myocarditis. J Am Coll Cardiol. 2017;69(13):1653-65.

33. Lopez-Ayala JM, Pastor-Quirante F, Gonzalez-Carrillo J, et al. Genetics of myocarditis in arrhythmogenic right ventricular dysplasia. Heart Rhythm. 2015;12(4):766-73. 
34. Wang C, Wong J, Fung G, et al. Dysferlin deficiency confers increased susceptibility to coxsackievirus-induced cardiomyopathy. Cell Microbiol. 2015;17:1423-30.

35. Badorff C, Lee GH, Lamphear BJ, et al. Enteroviral protease 2A cleaves dystrophin: evidence of cytoskeletal disruption in an acquired cardiomyopathy. Nat Med. 1999;5:320-6.

36. Xiong D, Lee GH, Badorff C, et al. Dystrophin deficiency markedly increases enterovirus-induced cardiomyopathy: a genetic predisposition to viral heart disease. Nat Med. 2002;8:872-7.

37. Diegoli M, Grasso M, Favalli V, et al. Diagnostic work-up and risk stratification in X-linked dilated cardiomyopathies caused by dystrophin defects. J Am Coll Cardiol. 2011;58:925-34.

38. Badorff C, Knowlton KU. Dystrophin disruption in enterovirus-induced myocarditis and dilated cardiomyopathy: from bench to bedside. Med Microbiol Immunol. 2004;193(2-3):121-6.

39. Lee GH, Badorff C, Knowlton KU. Dissociation of sarcoglycans and the dystrophin carboxyl terminus from the sarcolemma in enteroviral cardiomyopathy. Circ Res. 2000;87(6):489-95.

40. Garmaroudi FS, Marchant D, Hendry R, et al. Coxsackievirus B3 replication and pathogenesis. Future Microbiol. 2015;10:629-53.

41. Jiang M, Wei D, Ou WL, et al. Autopsy findings in children with hand, foot, and mouth disease. N Engl J Med. 2012;367(1):91-2.

42. Chang LY, Lin TY, Hsu KH, et al. Clinical features and risk factors of pulmonary oedema after enterovirus-71-related hand, foot, and mouth disease. Lancet. 1999;354:1682-6.

43. Verma NA, Zheng XT, Harris MU, et al. Outbreak of life-threatening coxsackievirus B1 myocarditis in neonates. Clin Infect Dis. 2009;49:759-63.

44. Wikswo ME, Khetsuriani N, Fowlkes AL, et al. Increased activity of Coxsackievirus B1 strains associated with severe disease among young infants in the United States, 2007-2008. Clin Infect Dis. 2009;49:e44-51.

45. Duintjer Tebbens RJ, Pallansch MA, et al. Oral poliovirus vaccine evolution and insights relevant to modeling the risks of circulating vaccine-derived polioviruses (cVDPVs). Risk Anal. 2013;33(4):680-702.

46. Antona D, Kossorotoff M, Schuffenecker I, et al. Severe paediatric conditions linked with EV-A71 and EV-D68, France, May to October 2016. Euro Surveill. 2016;21(46):30402.

47. Shi Y, Chen C, Lisewski U, Wrackmeyer U, et al. Cardiac deletion of the coxsackievirusadenovirus receptor abolishes coxsackievirus B3 infection and prevents myocarditis in vivo. $\mathrm{J}$ Am Coll Cardiol. 2009;53:1219-26.

48. Noutsias M, Fechner H, de Jonge H, et al. Human coxsackie-adenovirus receptor is colocalized with integrins alpha(v)beta(3) and alpha(v)beta(5) on the cardiomyocyte sarcolemma and upregulated in dilated cardiomyopathy: implications for cardiotropic viral infections. Circulation. 2001;104:275-80.

49. Jagdeo JM, Dufour A, Fung G, et al. Heterogeneous nuclear ribonucleoprotein M facilitates enterovirus infection. J Virol. 2015;89:7064-78.

50. Alirezaei M, Flynn CT, Wood MR, Harkins S, Whitton JL. Coxsackievirus can exploit LC3 in both autophagy-dependent and-independent manners in vivo. Autophagy. 2015;11:1389-407.

51. Robinson SM, Tsueng G, Sin J, et al. Coxsackievirus B exits the host cell in shed microvesicles displaying autophagosomal markers. PLoS Pathog. 2014;10:e1004045.

52. Hemida MG, Ye X, Zhang HM, et al. MicroRNA-203 enhances coxsackievirus B3 replication through targeting zinc finger protein-148. Cell Mol Life Sci. 2013;70:277-91.

53. Corsten MF, Papageorgiou A, Verhesen W, et al. MicroRNA profiling identifies microRNA-155 as an adverse mediator of cardiac injury and dysfunction during acute viral myocarditis. Circ Res. 2012;111:415-25.

54. Pagnamenta AT, Howard MF, Wisniewski E, et al. Germline recessive mutations in PI4KA are associated with perisylvian polymicrogyria, cerebellar hypoplasia and arthrogryposis. Hum Mol Genet. 2015;24(13):3732-41.

55. Bojjireddy N, Botyanszki J, Hammond G, et al. Pharmacological and genetic targeting of the PI4KA enzyme reveals its important role in maintaining plasma membrane phosphatidylinositol 4-phosphate and phosphatidylinositol 4,5-bisphosphate levels. J Biol Chem. 2014;289(9):6120-32. 
56. Lyoo H, van der Schaar HM, Dorobantu CM, et al. ACBD3 is an essential pan-enterovirus host factor that mediates the interaction between viral 3A protein and cellular protein PI4KB. MBio. 2019;10(1):e02742-18.

57. Tschöpe C, Müller I, Xia Y, et al. NOD2 (nucleotide-binding oligomerization domain 2) is a major pathogenic mediator of coxsackievirus B3-induced myocarditis. Circ Heart Fail. 2017;10(9):e003870.

58. Rogo LD, Mokhtari-Azad T, Kabir MH, Rezaei F. Human parvovirus B19: a review. Acta Virol. 2014;58:199-213.

59. Kerr JR. A review of blood diseases and cytopenias associated with human parvovirus B19 infection. Rev Med Virol. 2015;25:224-40.

60. Adamson-Small LA, Ignatovich IV, Laemmerhirt MG, et al. Persistent parvovirus B19 infection in non-erythroid tissues: possible role in the inflammatory and disease process. Virus Res. 2014;190:8-16.

61. Ganaie SS, Chen AY, Huang C, Xu P, Kleiboeker S, Du A, Qiu J. RNA binding protein RBM38 regulates expression of the 11-Kilodalton protein of parvovirus B19, which facilitates viral DNA replication. J Virol. 2018;92(8):e02050-17.

62. Xu P, Chen AY, Ganaie SS, Cheng F, Shen W, Wang X, Kleiboeker S, Li Y, Qiu J. The 11-kilodalton nonstructural protein of Human parvovirus B19 facilitates viral DNA replication by interacting with Grb2 through its Proline-rich motifs. J Virol. 2018;93(1):e01464-18.

63. Von Kietzell K, Pozzuto T, Heilbronn R, et al. Antibody-mediated enhancement of parvovirus B19 uptake into endothelial cells mediated by a receptor for complement factor C1q. J Virol. 2014;88:8102-15.

64. Kerr JR. The role of parvovirus B19 in the pathogenesis of autoimmunity and autoimmune disease. J Clin Pathol. 2016;69(4):279-91.

65. Koliou M, Karaoli E, Soteriades ES, et al. Acute hepatitis and myositis associated with erythema infectiosum by parvovirus B19 in an adolescent. BMC Pediatr. 2014;14:6.

66. Page C, Duverlie G, Sevestre H, et al. Erythrovirus B19 and autoimmune thyroid diseases. Review of the literature and pathophysiological hypotheses. J Med Virol. 2015;87:162-9.

67. Moimas S, Zacchigna S, Merlo M. Idiopathic dilated cardiomyopathy and persistent viral infection: lack of association in a controlled study using a quantitative assay. Heart Lung Circ. 2012;21:787-93.

68. Schenk T, Enders M, Pollak S, et al. High prevalence of human parvovirus B19 DNA in myocardial autopsy samples from subjects without myocarditis or dilative cardiomyopathy. J Clin Microbiol. 2009;47:106-10.

69. Linhartová K, Hubáček P, Zemánek D, Kodetová D, Zajac M, Setina M, Veselka J. Presence of the viral genome in the myocardial tissue of patients without clinical suspicion of myocarditis. Cardiovasc Pathol. 2013;22(1):113-4.

70. Santonja C, Santos-Briz A, Palmedo G, Kutzner H, Requena L. Detection of human parvovirus B19 DNA in $22 \%$ of 1815 cutaneous biopsies of a wide variety of dermatological conditions suggests viral persistence after primary infection and casts doubts on its pathogenic significance. Br J Dermatol. 2017;177(4):1060-5.

71. Molenaar-de Backer MW, Russcher A, Kroes AC, Koppelman MH, Lanfermeijer M, Zaaijer HL. Detection of parvovirus B19 DNA in blood: viruses or DNA remnants? J Clin Virol. 2016;84:19-23.

72. Greulich S, Kindermann I, Schumm J, et al. Predictors of outcome in patients with parvovirus B19 positive endomyocardial biopsy. Clin Res Cardiol. 2016;105(1):37-52.

73. Nguyen AB, Chung BB, Sayer G, Mullane K, Uriel N. Acute myocarditis secondary to reactivated chromosomally-integrated human herpesvirus 6. J Card Fail. 2017;23(7):576-7.

74. Pellett PE, Ablashi DV, Ambros PF, et al. Chromosomally-integrated HHV-6 (ciHHV-6) is a rarer condition in which the complete genome of the virus is integrated into the host germline genome chromosomally integrated human herpesvirus 6: questions and answers. Rev Med Virol. 2012;22(3):144-55.

75. Leong HN, Tuke PW, Tedder RS, et al. The prevalence of chromosomally integrated human herpesvirus 6 genomes in the blood of UK blood donors. J Med Virol. 2007;79:45-51. 
76. Daibata M, Taguchi T, Nemoto Y, Taguchi H, Miyoshi I. Inheritance of chromosomally integrated human herpesvirus 6 DNA. Blood. 1999;94:1545-9.

77. Kühl U, Lassner D, Wallaschek N, et al. Chromosomally integrated human herpesvirus 6 in heart failure: prevalence and treatment. Eur J Heart Fail. 2015;17:9-19.

78. Tweedy J, Spyrou MA, Hubacek P, Kuhl U, Lassner D, Gompels UA. Analyses of germline, chromosomally integrated human herpesvirus $6 \mathrm{~A}$ and $\mathrm{B}$ genomes indicate emergent infection and new inflammatory mediators. J Gen Virol. 2015;96(Pt 1.2):370-89.

79. Bern C. Chagas' disease. N Engl J Med. 2015;373(5):456-66.

80. Shikanai-Yasuda MA, Carvalho NB. Oral transmission of Chagas disease. Clin Infect Dis. 2012;54:845-52.

81. Garcia MN, Woc-Colburn L, Aguilar D, Hotez PJ, Murray KO. Historical perspectives on the epidemiology of human chagas disease in Texas and recommendations for enhanced understanding of clinical chagas disease in the Southern United States. PLoS Negl Trop Dis. 2015;9(11):e0003981.

82. World Health Organization. Chagas disease in Latin America: an epidemiological update based on 2010 estimates. Wkly Epidemiol Rec. 2015;90:33-43.

83. Sandri TL, Andrade FA, Lidani KCF, et al. Human collectin-11 (COLEC11) and its synergic genetic interaction with MASP2 are associated with the pathophysiology of Chagas disease. PLoS Negl Trop Dis. 2019;13(4):e0007324.

84. Leon Rodriguez DA, Carmona FD, Echeverría LE, González CI, Martin J. IL18 gene variants influence the susceptibility to Chagas disease. PLoS Negl Trop Dis. 2016;10(3):e0004583.

85. Leon Rodriguez DA, Carmona FD, González CI, Martin J. Evaluation of VDR gene polymorphisms in Trypanosoma cruzi infection and chronic Chagasic cardiomyopathy. Sci Rep. 2016;6:31263.

86. Reis PG, Ayo CM, de Mattos LC, et al. Genetic polymorphisms of IL17 and Chagas disease in the south and southeast of Brazil. J Immunol Res. 2017;2017:1017621.

87. Oliveira AP, Bernardo CR, Camargo AV, et al. Genetic susceptibility to cardiac and digestive clinical forms of chronic Chagas disease: involvement of the CCR5 59029 A/G polymorphism. PLoS One. 2015;10(11):e0141847.

88. Juiz NA, Estupiñán E, Hernández D, et al. Association study between CCR2-CCR5 genes polymorphisms and chronic Chagas heart disease in Wichi and in admixed populations from Argentina. PLoS Negl Trop Dis. 2019;13(1):e0007033.

89. Alvarado-Arnez LE, Batista AM, Alves SM, et al. Single nucleotide polymorphisms of cytokine-related genes and association with clinical outcome in a Chagas disease case-control study from Brazil. Mem Inst Oswaldo Cruz. 2018;113(6):e170489.

90. Clipman SJ, Henderson-Frost J, Fu KY, Bern C, Flores J, Gilman RH. Genetic association study of NLRP1, CARD, and CASP1 inflammasome genes with chronic Chagas cardiomyopathy among Trypanosoma cruzi seropositive patients in Bolivia. PLoS One. 2018;13(2):e0192378.

91. Leon Rodriguez DA, Acosta-Herrera M, Carmona FD, et al. Comprehensive analysis of three TYK2 gene variants in the susceptibility to Chagas disease infection and cardiomyopathy. PLoS One. 2018;13(1):e0190591.

92. Steer AC. Historical aspects of rheumatic fever. J Paediatr Child Health. 2015;51(1):21-7.

93. Bono-Neri F. Acute rheumatic fever: global persistence of a preventable disease. J Pediatr Health Care. 2017;31(3):275-84.

94. Zühlke LJ, Beaton A, Engel ME, et al. Group A streptococcus, acute rheumatic fever and rheumatic heart disease: epidemiology and clinical considerations. Curr Treat Options Cardiovasc Med. 2017;19(2):15.

95. Tian C, Hromatka BS, Kiefer AK, et al. Genome-wide association and HLA region finemapping studies identify susceptibility loci for multiple common infections. Nat Commun. 2017;8(1):599.

96. Wilson MG, Schweitzer MD, Lubschez R. The familial epidemiology of rheumatic fever: genetic and epidemiological studies. J Pediatr. 1943;97(2519):335-6. 
97. Patarroyo ME, Winchester RJ, Vejerano A, et al. Association of a B-cell alloantigen with susceptibility of rheumatic fever. Nature. 1979;278:173-4.

98. Zabriskie JB, Lavency D, Williams RC, et al. Rheumatic fever associated B-cell alloantigen as identified by monoclonal antibodies. Arthritis Rheum. 1985;28:1047-51.

99. Khanna AK, Buskirk RD, Williamsa RC Jr, et al. Presence of a non-HLA B cell antigen in rheumatic fever patients and their families as defined by a monoclonal antibody. J Clin Invest. 1989;83:1710-6.

100. Harel L, Zeharia A, Kodman Y, Straussberg R, Zabriskie JB, Amir J. Presence of the d8/17 B-cell marker in children with rheumatic fever in Israel. Clin Genet. 2002;61:293-8.

101. Engel ME, Stander R, Vogel J, Adeyemo AA, Mayosi BM. Genetic susceptibility to acute rheumatic fever: a systematic review and meta-analysis of twin studies. PLoS One. 2011;6(9):e25326.

102. Bhatt M, Kumar S, Siddiqui MH, Garg N, Mittal B. Influence of cytokine gene polymorphism on the risk of rheumatic heart disease - a meta-analysis. Immunol Lett. 2018;194:69-78.

103. Guilherme L, Kalil J. Rheumatic heart disease: molecules involved in valve tissue inflammation leading to the autoimmune process and anti-S. pyogenes vaccine. Front Immunol. 2013;4:352.

104. Matsushita M. Ficolins in complement activation. Mol Immunol. 2013;55(1):22-6.

105. Garred P, Honoré C, Ma YJ, Rørvig S, Cowland J, Borregaard N, Hummelshøj T. The genetics of ficolins. J Innate Immun. 2010;2(1):3-16.

106. Garred P, Borregaard N. The ficolins. J Innate Immun. 2010;2(1):1-2.

107. Honoré C, Hummelshoj T, Hansen BE, Madsen HO, Eggleton P, Garred P. The innate immune component ficolin 3 (Hakata antigen) mediates the clearance of late apoptotic cells. Arthritis Rheum. 2007;56:1598-607.

108. Rørvig S, Honore C, Larsson L-I, et al. Ficolin-1 is present in a highly mobilizable subset of human neutrophil granules and associates with the cell surface after stimulation with fMLP. J Leukoc Biol. 2009;86:1439-49.

109. Zhang J, Yang L, Ang Z, et al. Secreted M-Ficolin anchors onto monocyte transmembrane $\mathrm{G}$ protein-coupled receptor 43 and cross talks with plasma C-reactive protein to mediate immune signaling and regulate host defense. J Immunol. 2010;185:6899-910.

110. Kjaer TR, Hansen AG, Sørensen UBS, et al. Investigations on the pattern recognition molecule M-ficolin: quantitative aspects of bacterial binding and leukocyte association. J Leukoc Biol. 2011;90:425-37.

111. Ren Y, Ding Q, Zhang X. Ficolins and infectious diseases. Virol Sin. 2014;29:25-32.

112. Messias-Reason IJ, Schafranski MD, Kremsner PG, Kun JF. Ficolin 2 (FCN2) functional polymorphisms and the risk of rheumatic fever and rheumatic heart disease. Clin Exp Immunol. 2009;157(3):395-9.

113. Catarino SJ, Andrade FA, Boldt ABW, Guilherme L, Messias-Reason IJ. Sickening or healing the heart? The association of ficolin-1 and rheumatic fever. Front Immunol. 2018;9:3009.

114. Katayama M, Ota K, Nagi-Miura N, et al. Ficolin-1 is a promising therapeutic target for autoimmune diseases. Int Immunol. 2019;31(1):23-32.

115. Michalski M, Świerzko AS, Pagowska-Klimek I, et al. Primary Ficolin-3 deficiencyDOUBLEHYPHENis it associated with increased susceptibility to infections? Immunobiology. 2015;220(6):711-3.

116. Kumar P, Gupta D, Sagar RK. A rare combination of Marfan's syndrome, rheumatic heart disease and muscular dystrophyDOUBLEHYPHENa case report. Indian Heart J. 1994;46(6):351-2.

117. Lee LS, Rose CS, Maier LA. Sarcoidosis. N Engl J Med. 1997;336:1224-34.

118. Iannuzzi MC, Rybicki BA, Teirstein AS. Sarcoidosis. N Engl J Med. 2007;357(21):2153-65.

119. Chen ES, Moller DR. Etiologies of Sarcoidosis. Clin Rev Allergy Immunol. 2015;49: 6-18.

120. Rybicki BA, Major M, Popovich J Jr, et al. Racial differences in sarcoidosis incidence: a 5-year study in a health maintenance organization. Am J Epidemiol. 1997;145:234-41. 
121. Burke RR, Stone CH, Havstad S, Rybicki BA. Racial differences in sarcoidosis granuloma density. Lung. 2009;187:1-7.

122. Lynch JP, Hwang J, Bradfield J, et al. Cardiac involvement in sarcoidosis: evolving concepts in diagnosis and treatment. Semin Respir Crit Care Med. 2014;35:372-90.

123. Liu D, Birnbaum AD. Update on sarcoidosis. Curr Opin Ophthalmol. 2015;26:512-6.

124. Blau EB. Familial granulomatous arthritis, iritis, and rash. J Pediatr. 1985;107(5):689-93.

125. Miceli-Richard C, Lesage S, Rybojad M, et al. CARD15 mutations in Blau syndrome. Nat Genet. 2001;29(1):19-20.

126. Tan JL, Fong HK, Birati EY, Han Y. Cardiac Sarcoidosis. Am J Cardiol. 2019;123(3):513-22.

127. Iwai K, Tachibana $T$, Takemura $T$, et al. Pathological studies on sarcoidosis autopsy. I. Epidemiological features of 320 cases in Japan. Acta Pathol Jpn. 1993;43:372-6.

128. Iwai K, Takemura T, Kitaichi M, et al. Pathological studies on sarcoidosis autopsy. II. Early change, mode of progression and death pattern. Acta Pathol Jpn. 1993;43:377-85.

129. Crouser ED, Ono C, Tran T, et al. Improved detection of cardiac sarcoidosis using magnetic resonance with myocardial T2 mapping. Am J Respir Crit Care Med. 2014;189:109-12.

130. Wicks EC, Menezes LJ, Barnes A, et al. Diagnostic accuracy and prognostic value of simultaneous hybrid 18F-fluorodeoxyglucose positron emission tomography/magnetic resonance imaging in cardiac sarcoidosis. Eur Heart J Cardiovasc Imaging. 2018;19(7):757-67.

131. Karakaya B, Kaiser Y, van Moorsel CHM, Grunewald J. Löfgren's syndrome: diagnosis, management, and disease pathogenesis. Semin Respir Crit Care Med. 2017;38(4):463-76.

132. Blau Wouters CH, Maes A, Foley KP, Bertin J, Rose CD. Blau syndrome, the prototypic auto-inflammatory granulomatous disease. Pediatr Rheumatol Online J. 2014;12:33. https:// doi.org/10.1186/1546-0096-12-33.

133. Ebrahimiadib N, Samra KA, Domina AM, et al. A novel NOD2-associated mutation and variant blau syndrome: phenotype and molecular analysis. Ocul Immunol Inflamm. 2018;26(1):57-64.

134. Davoudi S, Navarro-Gomez D, Shen L, et al. NOD2 genetic variants and sarcoidosis-associated uveitis. Am J Ophthalmol Case Rep. 2016;3:39-42.

135. Whyte MP, Lim E, McAlister WH, et al. Unique variant of NOD2 pediatric granulomatous arthritis with severe 1,25-dihydroxyvitamin D-mediated hypercalcemia and generalized osteosclerosis. J Bone Miner Res. 2018;33(11):2071-80.

136. Milman N, Ursin K, Rødevand E, Nielsen FC, Hansen TV. A novel mutation in the NOD2 gene associated with Blau syndrome: a Norwegian family with four affected members. Scand J Rheumatol. 2009;38(3):190-7.

137. Li C, Zhang J, Li S, et al. Gene mutations and clinical phenotypes in Chinese children with Blau syndrome. Sci China Life Sci. 2017;60(7):758-62.

138. Mourad F, Tang A. Sinus of valsalva aneurysm in Blau's syndrome. J Cardiothorac Surg. 2010;5:16.

139. Touitou I, Lesage S, McDermott M, et al. Infevers: an evolving mutation database for autoinflammatory syndromes. Hum Mutat. 2004;24(3):194-8.

140. Takeuchi Y, Shigemura T, Kobayashi N, et al. Early diagnosis of early-onset sarcoidosis: a case report with functional analysis and review of the literature. Clin Rheumatol. 2017;36(5):1189-96.

141. Okada S, Konishi N, Tsumura M, et al. Cardiac infiltration in early-onset sarcoidosis associated with a novel heterozygous mutation, G481D, in CARD15. Rheumatology. 2009;48:706-7.

142. Rybicki BA, Sinha R, Iyengar S, the SAGA Study Consortium, et al. Genetic linkage analysis of sarcoidosis phenotypes: the sarcoidosis genetic analysis (SAGA) study. Genes Immun. 2007;8:379-86.

143. Fischer A, Grunewald J, Spagnolo P, et al. Genetics of Sarcoidosis. Semin Respir Crit Care Med. 2014;35:296-306.

144. Wolin A, Lahtela EL, Anttila V, et al. SNP variants in major histocompatibility complex are associated with sarcoidosis susceptibility-a joint analysis in four European populations. Front Immunol. 2017;8:422. 
145. Chaperon M, Pacheco Y, Maucort-Boulch D, Iwaz J, Perard L, Broussolle C, Jamilloux Y, Burillon C, Kodjikian L, Calender A, Seve P. BTNL2 gene polymorphism and sarcoid uveitis. Br J Ophthalmol. 2019;0:1-5. https://doi.org/10.1136/bjophthalmol-2018-312949.

146. Muller-Quernheim J, Schurmann M, Hofmann S, et al. Genetics of sarcoidosis. Clin Chest Med. 2008;29:391-414.

147. Kishore A, Petrek M. Immunogenetics of sarcoidosis. Int Trends Immun. 2013;1:43-53.

148. Fingerlin TE, Hamzeh N, Maier LA. Genetics of sarcoidosis. Clin Chest Med. 2015;36: 569-84.

149. Rivera NV, Ronninger M, Shchetynsky K, et al. High-density genetic mapping identifies new susceptibility variants in sarcoidosis phenotypes and shows genomic-driven phenotypic differences. Am J Respir Crit Care Med. 2016;193:1008-22.

150. Kishore A, Petersen BS, Nutsua M, et al. Whole-exome sequencing identifies rare genetic variations in German families with pulmonary sarcoidosis. Hum Genet. 2018;137(9): 705-16.

151. Rybicki BA, Iannuzzi MC, Frederick MM, et al. Familial aggregation of sarcoidosis. A case-control etiologic study of sarcoidosis (ACCESS). Am J Respir Crit Care Med. 2001;164:2085-91.

152. Baughman RP, Teirstein AS, Judson MA, Case Control Etiologic Study of Sarcoidosis (ACCESS) Research Group, et al. Clinical characteristics of patients in a case control study of sarcoidosis. Am J Respir Crit Care Med. 2001;164(10 Pt 1):1885-9.

153. Terwiel M, van Moorsel CHM. Clinical epidemiology of familial sarcoidosis: a systematic literature review. Respir Med. 2019;149:36-41.

154. Rossides M, Grunewald J, Eklund A, et al. Familial aggregation and heritability of sarcoidosis: a Swedish nested case control study. Eur Respir J. 2018;52(2):1800385.

155. Rossman MD, Thompson B, Frederick M, ACCESS Group, et al. HLA-DRB1*1101: a significant risk factor for sarcoidosis in blacks and whites. Am. J Hum Genet. 2003;73:720-35.

156. Naruse TK, Matsuzawa Y, Ota M, et al. HLA-DQB $1 * 0601$ is primarily associated with the susceptibility to cardiac sarcoidosis. Tissue Antigens. 2000;56(1):52-7.

157. Takashige N, Naruse TK, Matsumori A, Hara M, Nagai S, Morimoto S, Hiramitsu S, Sasayama S, Inoko H. Genetic polymorphisms at the tumour necrosis factor loci (TNFA and TNFB) in cardiac sarcoidosis. Tissue Antigens. 1999;54(2):191-3.

158. Grunewald J, Eklund A. Löfgren's syndrome: human leukocyte antigen strongly influences the disease course. Am J Respir Crit Care Med. 2009;179(4):307-12.

159. Rybicki BA, Walewski JL, Maliarik MJ, Kian H, Iannuzzi MC, ACCESS Research Group. The BTNL2 gene and sarcoidosis susceptibility in African Americans and whites. Am J Hum Genet. 2005;77:491-9.

160. Hofmann S, Franke A, Fischer A, et al. Genome-wide association study identifies ANXA11 as a new susceptibility locus for sarcoidosis. Nat Genet. 2008;40:1103-6.

161. Smith BN, Topp SD, Fallini C, et al. Mutations in the vesicular trafficking protein annexin A11 are associated with amyotrophic lateral sclerosis. Sci Transl Med. 2017;9:eaad9157.

162. Xu J, Brooks EG. Giant cell myocarditis: a brief review. Arch Pathol Lab Med. 2016;140(12):1429-34.

163. Vaideeswar P, Cooper L. Giant cell myocarditis: clinical and pathological disease characteristics in an Indian population. Cardiovasc Pathol. 2013;22:70-4.

164. Shariff S, Straatiamn L, Allard M, et al. Novel associations of giant cell myocarditis: two case reports and a review of the literature. Can J Cardiol. 2004;4:557-61.

165. Rosenstein ED, Zucker MJ, Kramer N. Giant cell myocarditis: most fatal of autoimmune diseases. Semin Arthritis Rheum. 2000;30(1):1-16.

166. Schumann C, Faust M, Gerharz M, et al. Autoimmune polyglandular syndrome associated with idiopathic giant cell myocarditis. Exp Clin Endocrinol Diabetes. 2005;113:302-7.

167. Varnavas VC, Reinsch N, Perrey M, et al. Recurrent lymphocytic myocarditis in a young male with ulcerative colitis. Eur J Med Res. 2014;19:11.

168. Joudinaud TM, Fadel E, Thomas-de-Montpreville V, et al. Fatal giant cell myocarditis after thymoma resection in myasthenia gravis. J Thorac Cardiovasc Surg. 2006;131:494-5. 
169. Sasaki H, Yano M, Kawano O, et al. Thymoma associated with fatal myocarditis and polymyositis in a 58-year-old man following treatment with carboplatin and paclitaxel: a case report. Oncol Lett. 2012;3:300-2.

170. Lee M, Kwon GY, Kim JS, et al. Giant cell myocarditis associated with Coxsackievirus infection. J Am Coll Cardiol. 2010;56:e19.

171. Dennert R, Schalla S, Suylen RJ, et al. Giant cell myocarditis triggered by a parvovirus B19 infection. Int J Cardiol. 2009;134:115-6.

172. Gkouziouta A, Miliopoulos D, Karavolias G, et al. Acute cytomegalovirus infection triggering fatal giant cell myocarditis. Int J Cardiol. 2016;214:204-6.

173. Ikeda Y, Inomata T, Nishinarita R, et al. Giant cell myocarditis associated with multiple autoimmune disorders following highly active antiretroviral therapy for human immunodeficiency virus type 1 infection. Int J Cardiol. 2016;206:79-81.

174. Bunu DM, Timofte CE, Ciocoiu M, et al. Cardiovascular manifestations of inflammatory bowel disease: pathogenesis, diagnosis, and preventive strategies. Gastroenterol Res Pract. 2019;2019:3012509. https://doi.org/10.1155/2019/3012509.

175. Asadi J, Bhandari SS, Ahmed N. Mesalazine-induced myopericarditis in a patient with ulcerative colitis. Echo Res Pract. 2017;5(1):K1-5.

176. Okoro KU, Roby MD, Bankole AA. Myocarditis secondary to mesalamine-induced cardiotoxicity in a patient with ulcerative colitis. Case Rep Med. 2018;2018:9813893. https://doi. org/10.1155/2018/9813893.

177. Mitoff PR, Mesana TG, Mielniczuk LM, et al. Giant cell myocarditis in a patient with a spondyloarthropathy after a drug hypersensitivity reaction. Can J Cardiol. 2013;29(9):1138.e7-8.

178. Priemer DS, Davidson DD, Loehrer PJ, Badve SS. Giant cell polymyositis and myocarditis in a patient with thymoma and myasthenia gravis: a postviral autoimmune process? J Neuropathol Exp Neurol. 2018;77(8):661-4.

179. Bechman K, Gopalan D, Nihoyannopoulos P, Mason JC. A cohort study reveals myocarditis to be a rare and life-threatening presentation of large vessel vasculitis. Semin Arthritis Rheum. 2017;47(2):241-6.

180. Stevens AW, Grossman ME, Barr ML. Orbital myositis, vitiligo, and giant cell myocarditis. J Am Acad Dermatol. 1996;35(2 Pt 2):310-2.

181. Chung L, Berry GJ, Chakravarty EF. Giant cell myocarditis: a rare cardiovascular manifestation in a patient with systemic lupus erythematosus. Lupus. 2005;14(2):166-9.

182. Rasmussen TB, Dalager S, Andersen NH, Hansen TK, Nielsen-Kudsk JE. Fatal giant cell myocarditis in a patient with multiple autoimmune disorders. BMJ Case Rep. 2009;2009:bcr09.2008.0997. https://doi.org/10.1136/bcr.09.2008.0997.

183. Martinez S, Miranda E, Kim P, Pollanen MS. Giant cell myocarditis associated with amoxicillin hypersensitivity reaction. Forensic Sci Med Pathol. 2013;9(3):403-6.

184. Rogers JS, Zakaria S, Thom KA, Flammer KM, Kanno M, Mehra MR. Immune reconstitution inflammatory syndrome and human immunodeficiency virus-associated myocarditis. Mayo Clin Proc. 2008;83(11):1275-9.

185. Hill AM, Mitchell N, Hughes S, Pozniak AL. Risks of cardiovascular or central nervous system adverse events and immune reconstitution inflammatory syndrome, for dolutegravir versus other antiretrovirals: meta-analysis of randomized trials. Curr Opin HIV AIDS. 2018;13(2):102-11.

186. Kong G, Madden B, Spyrou N, et al. Response of recurrent giant cell myocarditis in a transplanted heart to intensive immunosuppression. Eur Heart J. 1991;12:554-7.

187. Maleszewski JJ, Orellana VM, Hodge DO, et al. Long-term risk of recurrence, morbidity and mortality in giant cell myocarditis. Am J Cardiol. 2015;115:1733-8.

188. Larsen BT, Maleszewski JJ, Edwards WD, et al. Atrial giant cell myocarditis: a distinctive clinicopathologic entity. Circulation. 2013;127(1):39-47.

189. Bose AK, Bhattacharjee M, Martin V, Kendall S. Giant cell myocarditis of the left atrium. Cardiovasc Pathol. 2010;19(2):e37-8.

190. Shih JA, Shih JA. Small steps for idiopathic giant cell myocarditis. Curr Heart Fail Rep. 2015;12:263-8. 
191. Fanos V, Cuccu A, Nemolato S, Marinelli V, Faa G. A new nonsense mutation of the IGHMBP2 gene responsible for the first case of SMARD1 in a Sardinian patient with giant cell hepatitis. Neuropediatrics. 2010;41(3):132-4.

192. Kon T, Mori F, Tanji K, Miki Y, Kimura T, Wakabayashi K. Giant cell polymyositis and myocarditis associated with myasthenia gravis and thymoma. Neuropathology. 2013;33(3): 281-7.

193. Huang K, Shojania K, Chapman K, Amiri N, Dehghan N, Mezei M. Concurrent inflammatory myopathy and myasthenia gravis with or without thymic pathology: a case series and literature review. Semin Arthritis Rheum. 2019;48(4):745-51.

194. Gilhus NE, Nacu A, Andersen JB, Owe JF. Myasthenia gravis and risks for comorbidity. Eur J Neurol. 2015;22(1):17-23.

195. Saito N, Shimizu K, Kawaishi M, Araya J, Nakayama K, Kuwano K. A survival case of invasive thymoma accompanied by acute fulminant myocarditis. Respirol Case Rep. 2013;1(2):36-8.

196. Kittleson MM, Minhas KM, Irizarry RA, et al. Gene expression in giant cell myocarditis: altered expression of immune response genes. Int J Cardiol. 2005;102(2):333-40.

197. Asimaki A, Tandri H, Duffy E, et al. Altered desmosomal proteins in granulomatous myocarditis and potential pathogenic links to arrhythmogenic right ventricular cardiomyopathy. Circ Arrhythm Electrophysiol. 2011;4:743-52.

198. Wang SA. The diagnostic work-up of hypereosinophilia. Pathobiology. 2019;86(1):39-52.

199. Kita H. Eosinophils: multifaceted biological properties and roles in health and disease. Immunol Rev. 2011;242:161-77.

200. Valent P, Klion AD, Horny H-P, et al. Contemporary consensus proposal on criteria and classification of eosinophilic disorders and related syndromes. J Allergy Clin Immunol. 2012;130:607-612.e9.

201. Gotlib J. World Health Organization-defined eosinophilic disorders: 2011 update on diagnosis, risk stratification, and management. Am J Hematol. 2011;86:678-88.

202. Valent P, Gleich GJ, Reiter A, et al. Pathogenesis and classification of eosinophil disorders: a review of recent developments in the field. Expert Rev Hematol. 2012;5(2):157-76.

203. Simon H-U, Rothenburg ME, Bochner BS, et al. Refining the definition of hypereosinophilic syndrome. J Allergy Clin Immunol. 2010;126:45-9.

204. Crane MM, Chang CM, Kobayashi MG, et al. Incidence of myeloproliferative hypereosinophilic syndrome in the United States and an estimate of all hypereosinophilic syndrome incidence. J Allergy Clin Immunol. 2010;126:179-81.

205. Pardanani A, Ketterling RP, Li CY, et al. FIP1L1-PDGFRA in eosinophilic disorders: prevalence in routine clinical practice, long-term experience with imatinib therapy, and a critical review of the literature. Leuk Res. 2006;30:965-70.

206. Jovanovic JV, Score J, Waghorn K, et al. Low-dose imatinib mesylate leads to rapid induction of major molecular responses and achievement of complete molecular remission in FIP1L1PDGFRA-positive chronic eosinophilic leukemia. Blood. 2007;109:4635-40.

207. Giovannini-Chami L, Hadchouel A, Nathan N, et al. Idiopathic eosinophilic pneumonia in children: the French experience. Orphanet J Rare Dis. 2014;9:28.

208. Tamse T, Rampersad A, Jordan-Villegas A, Ireland J. A case of idiopathic hypereosinophilic syndrome causing mitral valve papillary muscle rupture. Case Rep Pediatr. 2015;2015:538762.

209. Tai CP, Chung T, Avasarala K. Endomyocardial fibrosis and mural thrombus in a 4-year-old girl due to idiopathic hypereosinophilia syndrome described with serial cardiac magnetic resonance imaging. Cardiol Young. 2016;26:168-71.

210. Helbig G, Wiśniewska-Piąty K, Francuz T, Dziaczkowska-Suszek J, Kyrcz-Krzemień S. Diversity of clinical manifestations and response to corticosteroids for idiopathic hypereosinophilic syndrome: retrospective study in 33 patients. Leuk Lymphoma. 2013;54:807-11.

211. Cools J, DeAngelo DJ, Gotlib J, et al. A tyrosine kinase created by fusion of the PDGFRA and FIP1L1 genes as a therapeutic target of imatinib in idiopathic hypereosinophilic syndrome. N Engl J Med. 2003;348:1201-14. 
212. Baccarani M, Cilloni D, Rondoni M, et al. The efficacy of imatinib mesylate in patients with FIP1L1-PDGFRalpha-positive hypereosinophilic syndrome. Results of a multicenter prospective study. Haematologica. 2007;92:1173-9.

213. Ogbogu PU, Bochner BS, Butterfield JH, et al. Hypereosinophilic syndromes: a multicenter, retrospective analysis of clinical characteristics and response to therapy. J Allergy Clin Immunol. 2009;124:1319-25.

214. Riley LK, Rupert J. Evaluation of patients with leukocytosis. Am Fam Physician. 2015;92(11):1004-11.

215. Mankad R, Bonnichsen C, Mankad S. Hypereosinophilic syndrome: cardiac diagnosis and management. Heart. 2016;102:100-6.

216. Séguéla PE, Iriart X, Acar P, Montaudon M, Roudaut R, Thambo JB. Eosinophilic cardiac disease: Molecular, clinical and imaging aspects. Arch Cardiovasc Dis. 2015;108(4):258-68.

217. Kleinfeldt T, Nienaber CA, Kische S, et al. Cardiac manifestation of the hypereosinophilic syndrome: new insights. Clin Res Cardiol. 2010;99:419-27.

218. Eicher JC, Bonnotte B, L'Huillier I, et al. Cardiovascular manifestations of eosinophilia: clinical and echocardiographic presentation. Rev Med Interne. 2009;30:1011-9.

219. Ginsberg F, Parrillo JE. Eosinophilic myocarditis. Heart Fail Clin. 2005;1(3):419-29.

220. Alyasin S, Khoshkhui M, Amin R. Familial Churg-Strauss syndrome in a sister and brother. Iran J Allergy Asthma Immunol. 2015;14(3):338-40.

221. Tsurikisawa N, Morita S, Tsuburai T, Oshikata C, Ono E, Taniguchi M, Saito H, Yanagihara Y, Akiyama K. Familial Churg-Strauss syndrome in two sisters. Chest. 2007;131(2): $592-4$.

222. Manganelli P, Giacosa R, Fietta P, Zanetti A, Neri TM. Familial vasculitides: ChurgStrauss syndrome and Wegener's granulomatosis in 2 first-degree relatives. J Rheumatol. 2003;30(3):618-21.

223. Schena S, Testa G, Setty S, Abcarian H, Benedetti E. Successful identical-twin living donor small bowel transplant for necrotizing enterovasculitis secondary to Churg-Strauss syndrome. Transpl Int. 2006;19(7):594-7.

224. Targońska-Stepniak B, Majdan M, Haberek G, Papuć E, Wnukowska K. Development of Churg-Strauss syndrome with severe multiple mononeuropathy after leukotriene receptor antagonist treatment in one of the monozygotic twins with asthma: case report. Pol Arch Med Wewn. 2009;119(11):761-4.

225. Martorana D, Maritati F, Malerba G, et al. PTPN22 R620W polymorphism in the ANCAassociated vasculitides. Rheumatology. 2012;51(5):805-12.

226. Wieczorek S, Holle JU, Bremer JP, et al. Contrasting association of a non-synonymous leptin receptor gene polymorphism with Wegener's granulomatosis and Churg-Strauss syndrome. Rheumatology. 2010;49(5):907-14.

227. Zwerina J, Bach C, Martorana D, et al. Eotaxin-3 in Churg-Strauss syndrome: a clinical and immunogenetic study. Rheumatology (Oxford). 2011;50(10):1823-7.

228. Human A, Murguia-Favela L, Benson L, Roifman I, Grunebaum E. Cardiovascular abnormalities in primary immunodeficiency diseases. Lympho Sign J. 2015;2(3):107-34.

229. Villa A, Notarangelo LD, Roifman CM. Omenn syndrome: inflammation in leaky severe combined immunodeficiency. J Allergy Clin Immunol. 2008;122(6):1082-6.

230. Chan Tack TA, Sandy S, Chan-Tack KM. Fatal cytomegalovirus myocarditis in an infant with Omenn's syndrome. Pediatr Infect Dis J. 2006;25(8):759-60.

231. Zago CA, Jacob CM, de Albuquerque Diniz EM, et al. Autoimmune manifestations in SCID due to IL7R mutations: Omenn syndrome and cytopenias. Hum Immunol. 2014;75(7):662-6.

232. Henderson LA, Frugoni F, Hopkins G, et al. First reported case of Omenn syndrome in a patient with reticular dysgenesis. J Allergy Clin Immunol. 2013;131(4):1227-9.

233. Brückmann C, Lindner W, Roos R, Permanetter W, Haas RJ, Haworth SG, Belohradsky $\mathrm{BH}$. Severe pulmonary vascular occlusive disease following bone marrow transplantation in Omenn syndrome. Eur J Pediatr. 1991;150(4):242-5.

234. Heyderman RS, Morgan G, Levinsky RJ, Strobel S. Successful bone marrow transplantation and treatment of BCG infection in two patients with severe combined immunodeficiency. Eur J Pediatr. 1991;150(7):477-80. 
235. Winkelstein JA, Marino MC, Lederman HM, et al. X-linked agammaglobulinemia: report on a United States registry of 201 patients. Medicine (Baltimore). 2006;85(4):193-202.

236. Rijkers GT, Holzer L, Dusselier T. Genetics in community-acquired pneumonia. Curr Opin Pulm Med. 2019;25(3):323-9.

237. Martínez Jaramillo C, Trujillo-Vargas CM. LRBA in the endomembrane system. Colomb Med (Cali). 2018;49(3):236-43.

238. Mardekian SK, Fortuna D, Nix A, et al. Severe human parechovirus type 3 myocarditis and encephalitis in an adolescent with hypogammaglobulinemia. Int J Infect Dis. 2015;36:6-8.

239. Scothorn DJ, Winick NJ, Timmons CF, Aquino VM. Rapidly fatal acute bacterial myocarditis in a nonneutropenic child with acute lymphoblastic leukemia in remission. J Pediatr Hematol Oncol. 2002;24(8):662-5.

240. Klein C. Genetic defects in severe congenital neutropenia: emerging insights into life and death of human neutrophil granulocytes. Annu Rev Immunol. 2011;29:399-413.

241. Boztug K, Appaswamy G, Ashikov A, et al. A syndrome with congenital neutropenia and mutations in G6PC3. N Engl J Med. 2009;360:32-43.

242. Banka S, Wynn R, Byers H, Arkwright PD, Newman WG. G6PC3 mutations cause nonsyndromic severe congenital neutropenia. Mol Genet Metab. 2013;108(2):138-41.

243. Boztug K, Rosenberg PS, Dorda M, et al. Extended spectrum of human glucose-6-phosphatase catalytic subunit 3 deficiency: novel genotypes and phenotypic variability in severe congenital neutropenia. J Pediatr. 2012;160:679-83.

244. Xia J, Bolyard AA, Rodger E, et al. Prevalence of mutations in ELANE, GFI1, HAX1, SBDS, WAS and G6PC3 patients with severe congenital neutropenia. Br J Haematol. 2009; 147:535-42.

245. McDermott DH, De Ravin SS, Jun HS, et al. Severe congenital neutropenia resulting from G6PC3 deficiency with increased neutrophil CXCR4 expression and myelokathexis. Blood. 2010;116:2793-802.

246. Dror Y, Donadieu J, Koglmeier J, et al. Draft consensus guidelines for diagnosis and treatment of Shwachman-Diamond syndrome. Ann N Y Acad Sci. 2011;1242:40-55.

247. Savilahti E, Rapola J. Frequent myocardial lesions in Shwachman's syndrome. Eight fatal cases among 16 Finnish patients. Acta Paediatr Scand. 1984;73:642-51.

248. Nivelon JL, Michiels R, Martres-Lassaunière MN, Passavy-Trouche AM, Petit A, Lorenzini JL. Myocardial fibrosis in Shwachman's syndrome: pathogenic discussion of cardiac complications. Pediatrie. 1978;33:461-9.

249. Graham AR, Walson PD, Paplanus SH, Payne CM. Testicular fibrosis and cardiomegaly in Shwachman's syndrome. Arch Pathol Lab Med. 1980;104:242-4.

250. Kopel L, Gutierrez PS, Lage SG. Dilated cardiomyopathy in a case of Shwachman-diamond syndrome. Cardiol Young. 2011;21:588-90.

251. Hauet Q, Beaupain B, Micheau M, et al. Cardiomyopathies and congenital heart diseases in Shwachman-Diamond syndrome: a national survey. Int J Cardiol. 2013;167(3):1048-50.

252. Toiviainen-Salo S, Pitkänen O, Holmström M, et al. Myocardial function in patients with Shwachman-Diamond syndrome: aspects to consider before stem cell transplantation. Pediatr Blood Cancer. 2008;51:461-7.

253. Ryan TD, Jefferies JL, Chin C, et al. Abnormal circumferential strain measured by echocardiography is present in patients with Shwachman-Diamond syndrome despite normal shortening fraction. Pediatr Blood Cancer. 2015;62(7):1228-31.

254. Pathak S, McDermott MF, Savic S. Autoinflammatory diseases: update on classification diagnosis and management. J Clin Pathol. 2017;70(1):1-8.

255. Comarmond C, Cacoub P. Myocarditis in auto-immune or auto-inflammatory diseases. Autoimmun Rev. 2017;16(8):811-6.

256. Broderick L. Hereditary autoinflammatory disorders: recognition and treatment. Immunol Allergy Clin N Am. 2019;39:13-29.

257. Consortium FF. A candidate gene for familial Mediterranean fever. Nat Genet. 1997;17:25-31.

258. McDermott MF, Aksentijevich I, Galon J, et al. Germline mutations in the extracellular domains of the $55 \mathrm{kDa}$ TNF receptor, TNFR1, define a family of dominantly inherited autoinflammatory syndromes. Cell. 1999;97:133-44. 
259. Masson V, Simon E, Hoppe P, et al. Tumor necrosis factor receptor-associated periodic syndrome (TRAPS): definition, semiology, prognosis, pathogenesis, treatment, and place relative to other periodic joint diseases. Joint Bone Spine. 2004;71:284-90.

260. Trost S, Rosé CD. Myocarditis and sacroiliitis: 2 previously unrecognized manifestations of tumor necrosis factor receptor associated periodic syndrome. J Rheumatol. 2005;32(1):175-7.

261. Parisi F, Paglionico A, Varriano V, Ferraccioli G, Gremese E. Refractory adult-onset still disease complicated by macrophage activation syndrome and acute myocarditis: a case report treated with high doses (8mg/kg/d) of anakinra. Medicine (Baltimore). 2017;96(24):e6656.

262. Zhou Q, Wang H, Schwartz DM, et al. Loss-of-function mutations in TNFAIP3 leading to A20 haploinsufficiency cause an early-onset autoinflammatory disease. Nat Genet. 2016;48(1):67-73.

263. Das T, Chen Z, Hendriks RW, Kool M. The A20/tumor necrosis factor $\alpha$-induced protein 3 in immune cells controls development of autoinflammation and autoimmunity: lessons from mouse models. Front Immunol. 2018;9:104.

264. Lawless D, Pathak S, Scambler TE, Ouboussad L, Anwar R, Savic S. A case of adult-onset still's disease caused by a novel splicing mutation in TNFAIP3 successfully treated with tocilizumab. Front Immunol. 2018;9:1527.

265. Gerfaud-Valentin M, Sève P, Iwaz J, et al. Myocarditis in adult-onset Still disease. Medicine (Baltimore). 2014;93:280-9.

266. Bank I, Marboe CC, Redberg RF, Jacobs J. Myocarditis in adult Still's disease. Arthritis Rheum. 1985;28(4):452-4.

267. Sachs RN, Talvard O, Lanfranchi J. Myocarditis in adult Still's disease. Int J Cardiol. 1990;27:377-80.

268. Gonzalez FA, Beirao P, Adriao J, Coelho ML. Adult-onset Still's disease presenting as myopericarditis. BMJ Case Rep. 2014;2014:bcr2013202754.

269. Luconi N, Risse J, Busato T, et al. Myocarditis in a young man with adult onset Still's disease successfully treated with Il-1 blocker. Int J Cardiol. 2015;189:220-2.

270. Cavallasca JA, Vigliano CA, Perandones CE, Tate GA. Myocarditis as a form of relapse in two patients with adult Still's disease. Rheumatol Int. 2010;30:1095-7.

271. Jadhav P, Nanayakkara N. Myocarditis in adult onset Stills disease. Int J Rheum Dis. 2009;12:272-4.

272. Baratta L, Delfino M, Fiorentini A, et al. Alterations of the sympathovagal balance evaluated by heart rate variability in a rare case of adult Still's disease. Ann Ital Med Int. 2004;19:193-7.

273. Gupta D, Jagani R, Mendonca S, Rathi KR. Adult-onset Still's disease with myocarditis and hemophagocytic lymphohistiocytosis: rare manifestation with fatal outcome. Indian J Pathol Microbiol. 2016;59:84-6.

274. Meckenstock R, Therby A, Gibault-Genty G, Khau D, Monnier S, Greder-Belan A. Adultonset Still's disease revealed by perimyocarditis and a concomitant reactivation of an EBV infection. BMJ Case Rep. 2012;2012:bcr0120113688.

275. Uggenti C, Lepelley A, Crow YJ. Self-awareness: nucleic acid-driven inflammation and the type I interferonopathies. Annu Rev Immunol. 2019;37:247-67.

276. Crow YJ. Aicardi-Goutières syndrome. 2005 Jun 29 [updated 2016 Nov 22]. In: Adam MP, Ardinger HH, Pagon RA, Wallace SE, Bean LJH, Stephens K, Amemiya A, editors. GeneReviews ${ }^{\circledR}$ [Internet]. Seattle: University of Washington, Seattle; 1993-2019. http:// www.ncbi.nlm.nih.gov/books/NBK1475/.

277. Crow YJ, Chase DS, Lowenstein Schmidt J, et al. Characterization of human disease phenotypes associated with mutations in TREX1, RNASEH2A, RNASEH2B, RNASEH2C, SAMHD1, ADAR, and IFIH1. Am J Med Genet A. 2015;0(2):296-312.

278. Morita M, Stamp G, Robins P, et al. Gene-targeted mice lacking the Trex1 (DNase III) 3'-->5' DNA exonuclease develop inflammatory myocarditis. Mol Cell Biol. 2004;24(15):6719-27.

279. Beck-Engeser GB, Eilat D, Wabl M. An autoimmune disease prevented by anti-retroviral drugs. Retrovirology. 2011;8:91.

280. Feigenbaum A, Muller C, Yale C, et al. Singleton-Merten syndrome: an autosomal dominant disorder with variable expression. Am J Med Genet. 2013;161A:360-70. 
281. Zhang X, Gao X, Hu J, et al. ADAR1p150 forms a complex with dicer to promote miRNA222 activity and regulate PTEN expression in CVB3-induced viral myocarditis. Int J Mol Sci. 2019;20(2):E407.

282. Adang LA, Frank DB, Gilani A, et al. Aicardi goutières syndrome is associated with pulmonary hypertension. Mol Genet Metab. 2018;125(4):351-8.

283. Nelson CP, Schunkert H, Samani NJ, Erridge C. Genetic analysis of leukocyte type-I interferon production and risk of coronary artery disease. Arterioscler Thromb Vasc Biol. 2015;35(6):1456-62. 